OPEN ACCESS

Edited by:

Fabrizio Mattei,

Istituto Superiore di Sanità, Italy

Reviewed by:

Takahiro Yamazaki,

Institut Gustave Roussy, France

Bo Zhu,

Boston University, USA

${ }^{*}$ Correspondence:

Alain Lamarre

alain.lamarre@iaf.inrs.ca

Specialty section:

This article was submitted to

Molecular Innate Immunity,

a section of the journal

Frontiers in Immunology

Received: 31 August 2016 Accepted: 22 November 2016 Published: 05 December 2016

Citation:

Daugan M, Murira A, Mindt BC,

Germain A, Tarrab E, Lapierre P. Fritz JH and Lamarre A (2016) Type I Interferon Impairs Specific Antibody

Responses Early during Establishment of LCMV Infection.

Front. Immunol. 7:564. doi: 10.3389/fimmu.2016.00564

\section{Type I Interferon Impairs Specific Antibody Responses Early during Establishment of LCMV Infection}

\author{
Matthieu Daugan', Armstrong Murira', Barbara C. Mindt'², Amélie Germain', \\ Esther Tarrab ${ }^{1}$, Pascal Lapierre ${ }^{1}$, Jörg H. Fritz ${ }^{2,3}$ and Alain Lamarre ${ }^{1 *}$ \\ 1 Immunovirology Laboratory, Institut national de la recherche scientifique (INRS), INRS-Institut Armand-Frappier, Laval, QC, \\ Canada, ${ }^{2}$ Complex Traits Group, Department of Microbiology and Immunology, McGill University, Montréal, QC, Canada, \\ ${ }^{3}$ Complex Traits Group, Department of Physiology, McGill University, Montréal, QC, Canada
}

Elicitation of type I interferon (IFN-I) has been shown to both enhance and impair cell-mediated immune responses in acute and persistent viral infections, respectively. Here, we show that, in addition to its effect on T cells, IFN-I drives impairment of specific antibody responses through interaction with $\mathrm{B}$ cells in the acute phase of lymphocytic choriomeningitis virus (LCMV) infection. This impairment was limited to the T cell-dependent B cell response and was associated with disruption of B cell follicles, development of hypergammaglobulinemia (HGG), and expansion of the $T$ follicular helper cell population. Antigen-specific antibody responses were restored by ablation of IFN-I signaling through antibody-mediated IFN-I receptor blockade and B cell-specific IFN-I receptor knockout. Importantly, IFN-I receptor deficiency in B cells also accelerated the development of LCMV neutralizing antibodies and alleviated HGG. These results provide a potential therapeutic target toward efficient treatment measures that limit immunopathology in persistent viral infections.

Keywords: LCMV, interferon type I, antibody formation, immunopathology, neutralizing antibodies

\section{INTRODUCTION}

The humoral immune response plays a central effector role against viral infection whereby induction of effective antibody $(\mathrm{Ab})$ responses serves as an important correlate toward pathogen clearance. However, during persistent viral infections, e.g., with human immunodeficiency virus (HIV), hepatitis $\mathrm{C}$ virus (HCV), or the murine infection model lymphocytic choriomeningitis virus (LCMV), emergence of neutralizing Abs (nAbs) against these highly mutable viruses is delayed, initially narrow in specificity and ineffective against the established infection; as such, the Ab response bears negligible impact on the progression of the disease (1). Accompanying the delayed induction of nAbs, infected hosts also exhibit an altered immunological milieu that features aberrancies to the humoral response such as: (i) dysregulation of B cell subpopulations $(2,3)$; (ii) hypergammaglobulinemia (HGG) $(4,5)$; (iii) increase of polyreactive $A b s(6,7)$; and (iv) impaired response to vaccines $(4,8)$. Altogether, these perturbations result in a diminished antigen-specific Ab response and an enhanced non-specific polyclonal response. Notably, these immunomodulatory effects are driven directly by viral pathogenic mechanisms and indirectly through immunopathogenesis triggered by host antiviral responses (9). Presently, it is yet to be determined whether this immunological disruption occurs as a function of chronicity or due to mechanisms initiated during the acute stage of the viral infection. 
Concomitant with dysregulation of the humoral immune response, an increase in $\mathrm{T}$ follicular helper $\left(\mathrm{T}_{\mathrm{FH}}\right)$ cells has also been observed during persistent HIV (10) and HCV (11) infections as well as the chronic phase of LCMV infection (12). In the LCMV model, expansion of $\mathrm{T}_{\mathrm{FH}}$ cells has been attributed to polarization of the CD4 $\mathrm{T}$ cell compartment toward $\mathrm{T}_{\mathrm{FH}}$ responses, which suggests a role of cytokines such as type I interferon (IFN-I) that skew differentiation and maturation toward $\mathrm{T}_{\mathrm{FH}}$ and away from $\mathrm{T}$ helper type $1\left(\mathrm{~T}_{\mathrm{H}} 1\right)$ cells (13). The role of IFN-I signaling with respect to $\mathrm{T}$ cells is well characterized and increasing evidence shows that this antiviral cytokine has both enhancing and immunosuppressive effects on the T cell response upon viral infection $(14,15)$. Two recent studies clearly outlined the bipolar effect that IFN-I renders on T cell-mediated immune responses by comparing the expression profile of IFN-I and IFN-stimulated genes (ISGs) in LCMV Armstrong (acute) versus LCMV Clone 13 (Cl13; persistent) infection $(16,17)$. Collectively, this research revealed that although protective upon transient elicitation such as in acute infections, prolonged elevation of IFN-I levels postinfection led to immunosuppression of $\mathrm{T}$ cell responses. In these studies, sustained expression of IFN-I was shown to drive upregulation of immunosuppressive molecules such as PD-1 and IL10 as well as disruption of splenic architecture and dampened effector CD8+ T cell (CTL) responses (16-21). Altogether, this contributes to the failure of viral clearance and eventual persistent infection.

Similarly, IFN-I production has also been shown to enhance the development of the $\mathrm{Ab}$ response against acute viral infections or vaccine antigens (22-27). Akin to T cells, the effect of IFN-I on $\mathrm{B}$ cell responses has been shown to drive increased cellular activation and class switching recombination (CSR) in the T-celldependent arm of the humoral immune response (23, 25, 27-29). The upregulation of ISGs in B cells from HIV-viremic patients (30) is also indicative of a role played by IFN-I during chronic infections.

However, unlike the deleterious role played by the cytokine against $\mathrm{T}$-cell responses during persistent infection, the effect of IFN-I on B cell responses in this context is yet to be fully elucidated. In this report, we use the LCMV mouse model to further characterize the molecular mechanisms that drive the modulation and resulting humoral immune dysregulation during persistent virus infection.

\section{RESULTS}

\section{LCMV Infection Impairs the Humoral Response to T-Dependent Antigens}

Although the influence of escape mutations within the glycoprotein envelope of LCMV as well as dysregulated T cell responses have been implicated in the late appearance of nAbs (31-33), it is unclear whether broader modulation of the immune response also contributes to the disrupted $\mathrm{Ab}$ response. To directly evaluate this, we analyzed the $\mathrm{Ab}$ response against the model T-dependent (TD) antigen, nitrophenyl (NP) coupled to chicken gamma globulin (CGG) in the context of CTL-controlled LCMV $(34,35)$, and Ab-controlled vesicular stomatitis virus (VSV) infection (36). The focal point of these experiments was based on the NP response rather than comparing the antiviral response to clearly distinguish and determine modulation to the global immune response independent of LCMV versus VSV whose pathogenic determinants drive distinctive responses. C57BL/6 (B6) mice were infected with either LCMV Cl13 or LCMV WE (acute); VSV Indiana or mock infected with culture media only. All groups were contemporaneously immunized with NP-CGG, which predominantly elicits an IgG1 response (37). At various time points after immunization, the NP-specific IgG1 serum response was monitored by ELISA, which revealed that $\mathrm{Ab}$ titers were drastically reduced in LCMV Cl13-infected mice, compared to VSV-infected or mock-infected control mice (Figure 1A). Furthermore, this impairment was also present albeit to a lesser extent in mice infected with LCMV WE (Figures 1A,B, left panel). Although LCMV-Cl13-associated impairment of NP-specific responses declined after day (d)12, the increase in the IgG1 responses thereafter did not attain the levels observed in VSV-infected or mock-infected groups for the duration of the experiment (30 days) (Figure 1A). The kinetics of the disrupted NP-specific response and the impact by both the acute and persistent strains of LCMV suggest that the immunological process that drives this phenotype occurs early after infection whereas the $\mathrm{Cl} 13$ strain featured more adverse impairment due to viral persistence. Upon infection with LCMV Cl13 or VSV as above and simultaneous immunization with a T-independent Type 2 (TI-2) antigen, NP-FICOLL, NP-specific IgG3 (Figure 1C), and IgM (Figure 1D) responses were similar in all groups although a trend toward weaker IgM responses in the LCMV-infected group was observed at latter time points. These results demonstrate that LCMV predominantly impairs the TD response. Similar results were also observed in LCMV WE-infected mice (data not shown). Despite the impairment of the TD response, however, the affinity maturation process was unaltered by LCMV Cl13 infection. As illustrated in Figure 1E, the ratio of high affinity anti-NP IgG1 Abs binding to $\mathrm{NP}_{4^{-}}$ BSA versus the total anti-NP IgG1 response, measured using $\mathrm{NP}_{26}$-BSA, reflected a similar increase in Ab affinity at various time points in all three experimental groups. Again, similar results were observed for LCMV WE (data not shown). Thus, although diminished in serum concentration, the quality of the NP-specific response was not affected by LCMV infection. Importantly, the reduction in the NP-specific IgG1 response occurs in the context of increased total IgG serum levels that is evident by $\mathrm{d} 12$ in LCMV Cl13- and d8 in LCMV WE-infected mice compared to VSV- or mock-infected animals (Figure 1F). These results are in agreement with the emergence of polyclonal non-specific B cell activation and resultant HGG that is observed during LCMV infection (38) and other persistent viral infections such as HIV $(4,6)$ or HCV (39).

To further characterize the duration of LCMV-associated effects on the NP-specific response, we immunized mice 4 days before (d-4) and on d4, d8, d12, d20, or d30 after LCMV WE or VSV infections (Figure S1 in Supplementary Material). In this particular experiment, the kinetics of viral clearance within a limited window are important to facilitate accurate assessment of the effect of Ab-response impairment by LCMV. As such, 


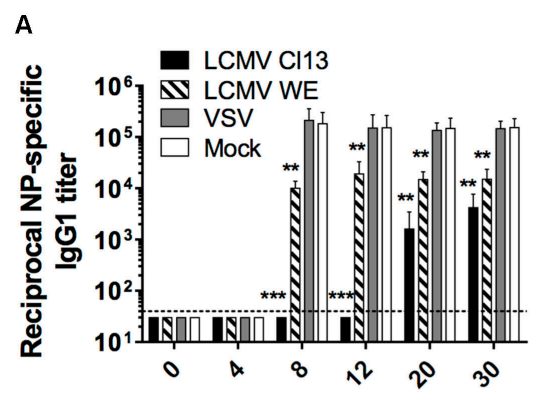

Time after immunization (d)

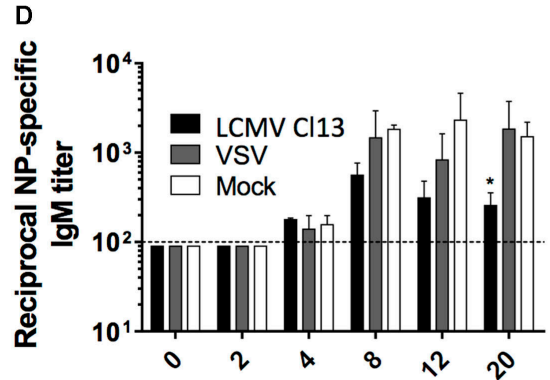

Time after immunization (d)

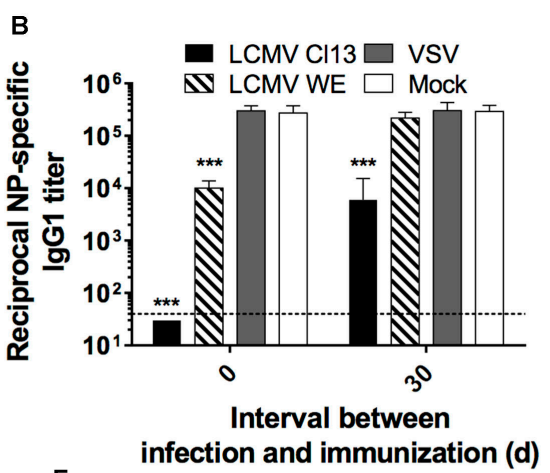

E

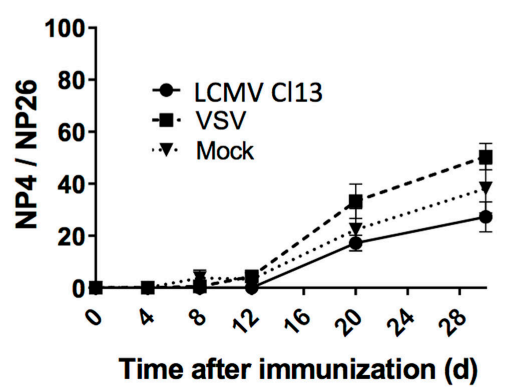

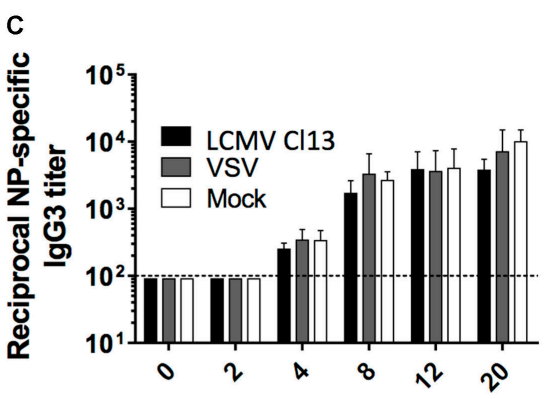

Time after immunization (d)

$\mathbf{F}$

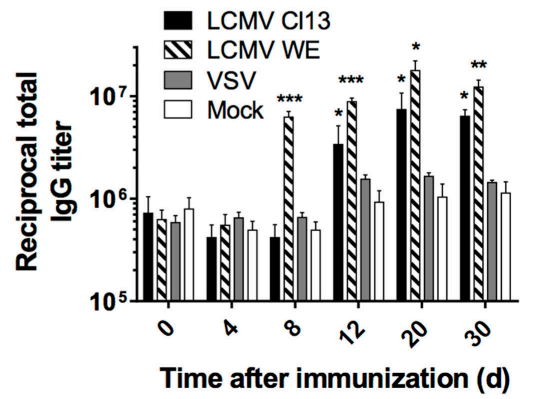

FIGURE 1 | LCMV infection impairs the NP-specific Ab response in a T cell-dependent manner. B6 mice (four per group) were infected with LCMV Cl13 (black), LCMV WE (hatched), VSV (gray), or mock infected (white). Mice were immunized the same day (except when indicated otherwise) with an i.p. injection of $\mathrm{NP}_{53}$-CGG in alum (A,B,E,F) or NP 40 -FICOLL in PBS (C,D). (A) NP-specific IgG1 response monitored by ELISA following NP 53 $^{-}$-CGG immunization. (B) Mice were infected as above and immunized with $\mathrm{NP}_{53}$-CGG the same day (d0) or 30 days after infection (d30), and IgG1 NP-specific responses were monitored by ELISA on d8 postimmunization. NP-specific IgG3 (C) or IgM (D) responses monitored by ELISA following NP ${ }_{40}$-FICOLL immunization. (E) ELISA plates were coated with NP ${ }_{4}$-BSA or $\mathrm{NP}_{26}$ - $\mathrm{BSA}$ and high affinity $\mathrm{Ab}$ responses were measured as a ratio of Abs binding to $\mathrm{NP}_{4}-\mathrm{BSA}$ versus the total anti-NP IgG1 response binding to $\mathrm{NP}_{26}-\mathrm{BSA}$. (F) Total serum IgG responses following concomitant infection and NP ${ }_{53}$-CGG immunization. Statistical analysis was performed by individual $T$-tests between experimental groups and the mock-infected group. ${ }^{\star} p<0.05,{ }^{\star \star} p<0.01,{ }^{\star \star \star} p<0.001$. The dotted line represents detection threshold. (A-E) Representative of two independent experiments. (F) Representative of four independent experiments.

the acute strain, LCMV WE, was used given that this variant is cleared from lymphoid organs within about a week (35). As shown in Figure S1A in Supplementary Material, the Ab response in the VSV-infected group was unaffected irrespective of the time interval between infection and immunization. On the other hand, NP-specific IgG1 responses in LCMV WE-infected mice revealed similar levels of impairment upon immunization on $\mathrm{d} 4, \mathrm{~d} 8$, and $\mathrm{d} 12$ postimmunization. However, the impact on the NP-specific response upon immunization on $\mathrm{d} 4$ before or $\mathrm{d} 20$ after infection was less severe relative to the other time points. This indicates that B cell responses: (i) were less susceptible to LCMV impairment if established prior to infection; (ii) start to recover by $\mathrm{d} 20$ following LCMV WE infection before returning to normal levels by $\mathrm{d} 30$ postinfection; and (iii) remain impaired past $\mathrm{d} 30$ following infection with LCMV Cl13 (Figure 1B, right panel). Finally, changes in affinity maturation did not attain statistical significance irrespective of the time interval between LCMV infection and immunization (Figure S1B in Supplementary Material). Taken together, these results indicate that LCMV impairs the development of specific Ab responses early following establishment of infection, which is sustained in the context of persistent infection.

\section{LCMV Infection Modifies the Lymphoid Microenvironment and B Cell Function}

To gain further insight into the immunological milieu within which the impairment of TD NP-specific Ab responses occurred, we evaluated $\mathrm{B}$ cell populations and the splenic microenvironment in the three infection groups on $\mathrm{d} 8$ postinfection/ immunization. Similar to a previous report (40), we observed perturbations in the splenic architecture whereby immunohistochemistry revealed a dramatic disruption of $\mathrm{B}$ cell follicles in LCMV-infected mice relative to VSV- and mock-infected controls with B cells being mostly found outside of the follicles (Figure 2A). Counterintuitive to this disruption, while total numbers and proportions of splenic B cells were contracted in the LCMV Cl13-infected group (Figure 2B), the number and proportion of GC B cells were significantly increased (Figure 2C). Expansion of the GC B cell population suggested enhanced activation of $\mathrm{B}$ cells in the LCMV group. Given that this phenomenon could lead to increased differentiation into effector B cell subsets [e.g., plasma cells (PCs)], we evaluated the splenic Ab-secreting cell (ASC) population on d8 after infection and immunization with NP-CGG using ELISPOT (Figure 2D). In agreement with the expansion of GC B cells and the presence 
of HGG, the total number of IgG-secreting cells in the LCMV Cl13-infected group was elevated. Conversely, the quantity of NP-specific IgG-secreting cells was significantly decreased in the LCMV Cl13 group, correlating with the depressed antigenspecific Ab response. Similar results were also observed in the bone marrow compartment to which the PCs migrate after
A

A

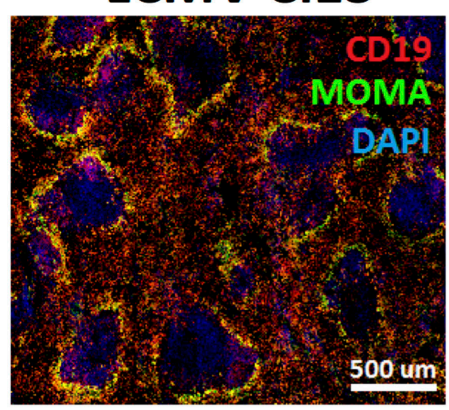

VSV

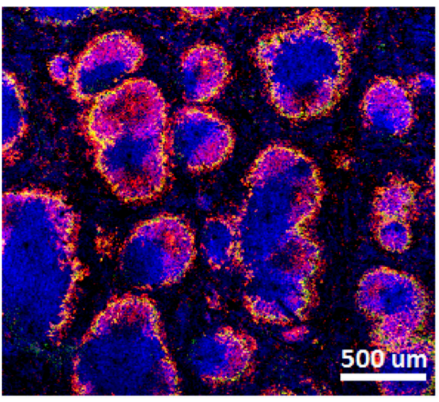

Mock

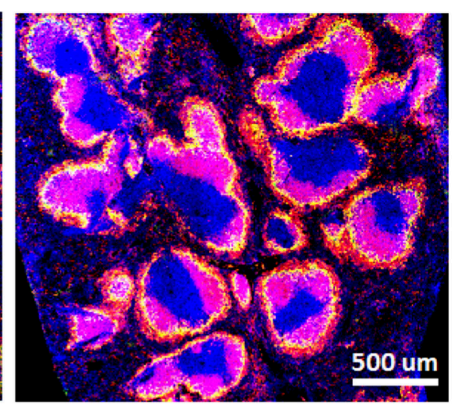

B

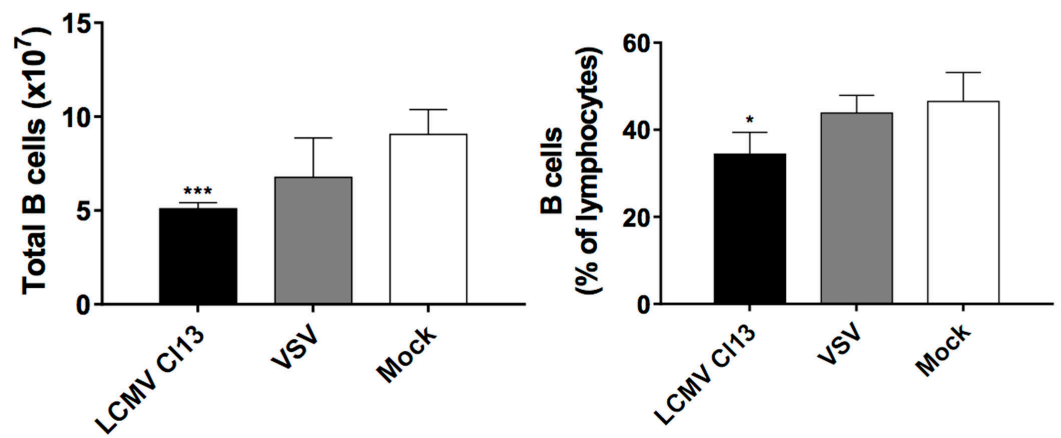

C
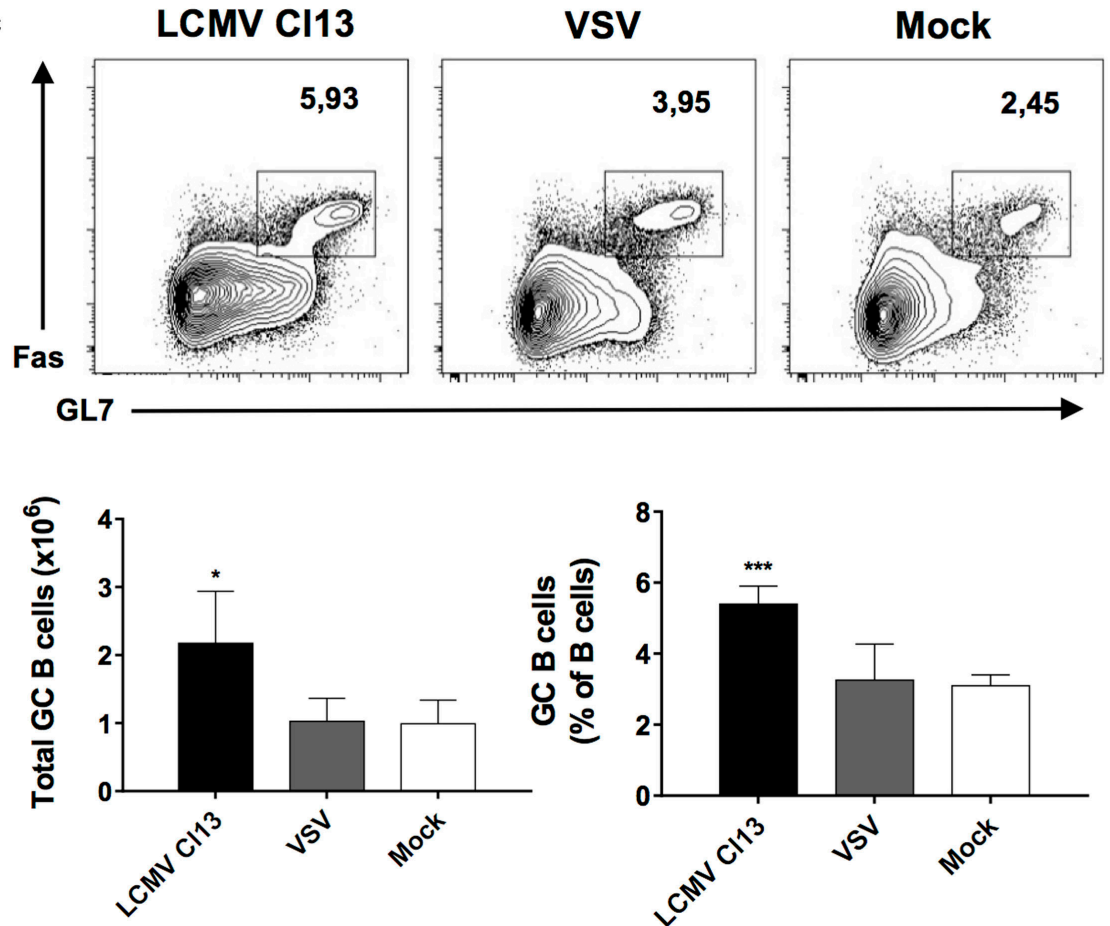

FIGURE 2 | LCMV infection disrupts the splenic follicular architecture while increasing GC B cell numbers and non-specific Ab responses 

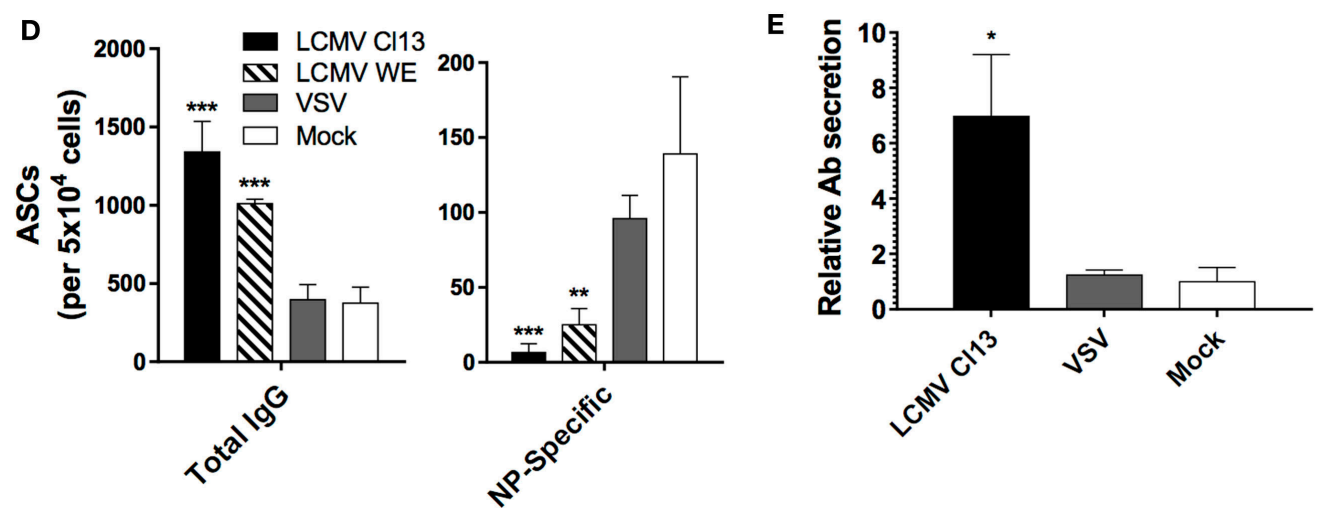

FIGURE 2 | Continued

B6 mice (four per group) were infected with LCMV Cl13 (black), LCMV WE (hatched), VSV (gray), or mock infected (white). Mice were immunized the same day with an i.p. injection of $\mathrm{NP}_{53}-\mathrm{CGG}$ in alum and TD B cell responses were analyzed on d8 after infection. (A) Immunofluorescence showing CD19 (red), MOMA-1 (green), and DAPI (blue) expression on spleen sections. (B) Total B cell numbers and proportions were enumerated by flow cytometry. (C) Number and proportion of splenic GC B cells. (D) Number of total and NP-specific IgG-secreting cells detected by ELISPOT. (E) Relative Ab secretion of ASCs calculated by ex vivo measurement of secreted Abs produced by $10^{5}$ splenocytes. Statistical analysis was performed by individual T-tests between experimental groups and the mock-infected group. ${ }^{\star} p<0.05,{ }^{* \star} p<0.01,{ }^{* \star *} p<0.001$. (A) Representative of two independent experiments. (B-E) Representative of four independent experiments.

differentiation in the secondary lymphoid organs (data not shown) and these features were observed in LCMV WE-infected animals as well (Figure 2D). Last, consistent with the increase in the number of IgG-secreting ASCs due to polyclonal B cell activation during LCMV infection (38), ASCs from this group also displayed an increased secretory capacity (Figure 2E). Expressed here as a ratio, the ex vivo Ab concentration from splenic ASCs was quantified from culture supernatants, which revealed that following LCMV Cl13 infection, ASCs secreted a significantly higher quantity of Ab relative to VSV- or mock-infected mice.

\section{LCMV Infection Triggers the Expansion of $T_{F H}$ and an Increase in Their Effector Function}

Upon phenotypic characterization of the CD4 T cell compartment, we observed that there was a contraction in the absolute number of CD4 $\mathrm{T}$ cells (Figure 3A, top panel), which was more evident in the proportion of $\mathrm{CD} 4 \mathrm{~T}$ cells relative to total lymphocytes in the LCMV-infected groups (Figure 3A, bottom panel). This coincided with a significant increase in the $\mathrm{T}_{\mathrm{FH}}$ compartment $\left(\mathrm{CD} 4{ }^{+} \mathrm{CD} 62 \mathrm{~L}^{-} \mathrm{CD} 44^{+} \mathrm{CXCR} 5^{+} \mathrm{Bcl}-6^{+}\right)$as shown in Figure $3 \mathrm{~B}$. These results are supported by previous work, which demonstrated that LCMV increased differentiation of CD4 $\mathrm{T}$ cells into $\mathrm{T}_{\mathrm{FH}}$, and this redirected differentiation program was sustained in LCMV Cl13 due to viral persistence (12). Based on these changes in the $\mathrm{T}_{\mathrm{FH}}$ population and their potential influence on the humoral immune response, we sought to determine whether the essential costimulatory and signaling molecules that comprise interaction between $\mathrm{T}_{\mathrm{FH}}$ and GC B cells were similarly modified during LCMV infection. Using phenotypic analysis by flow cytometry, we analyzed the expression of PD-1, which has been shown to be an ideal marker to distinguish GC from
non-GC $\mathrm{T}_{\mathrm{FH}}$ (41). Here, we observed a significantly higher proportion of $\mathrm{T}_{\mathrm{FH}}$ cells expressing increased levels of $\mathrm{PD}-1$ in LCMV Cl13-infected mice (Figure 3C) indicating a higher number of $\mathrm{GC}_{\mathrm{FH}}$ relative to the other cohorts. Likewise, proportions of $\mathrm{T}_{\mathrm{FH}}$ expressing high levels of ICOS were also significantly elevated relative to mock-infected controls, which was also the case for VSV-infected mice albeit to a lesser extent. Surprisingly, while proportions of B cells expressing PD-L1 similarly increased (Figure 3D), those expressing ICOSL were reduced whereas the ligand pair CD40:CD40L remained unchanged across the three infection groups (Figures 3C,D). Serum levels of BAFF were also elevated in LCMV Cl13-infected mice along with BAFF, IL-21, and IL-4 mRNA and protein expression in CD4 $\mathrm{T}$ cells (Figures $3 \mathrm{E}, \mathbf{F}$ ). As previously mentioned, predilection toward $\mathrm{T}_{\mathrm{FH}}$ differentiation in the context of persistent infection can occur as a result of prolonged expression of IFN-I. However, whether the effects on the humoral response are solely due to a modulated $\mathrm{T}_{\mathrm{FH}}$ response shaping the $\mathrm{B}$ cell response or more direct impact of IFN-I on the B cells is unknown. To determine the potential role of $\mathrm{T}_{\mathrm{FH}}$ immunomodulation on perturbation of the humoral response, we administered blocking Abs against PD-1, which comprises a key molecular interaction between GC $\mathrm{B}$ cells and $\mathrm{T}_{\mathrm{FH}}$ (42). The LCMV WE strain was used here given that interfering with the PD-1 pathway during the early phase of systemic LCMV Cl13 infection has been shown to induce lethal CD8 T cell-mediated immunopathology $(18,43)$. As illustrated in Figure 3G, blockade of PD-1 prior to infection and immunization with NP did not alter the NP-specific and total IgG titers relative to the untreated control group. Similar results were obtained following PD-L1 blockade (data not shown). Therefore, in our model, humoral disruption was immutable to blockade of the PD-1 pathway suggesting a more direct role of IFN-I on $B$ cell function. 
A

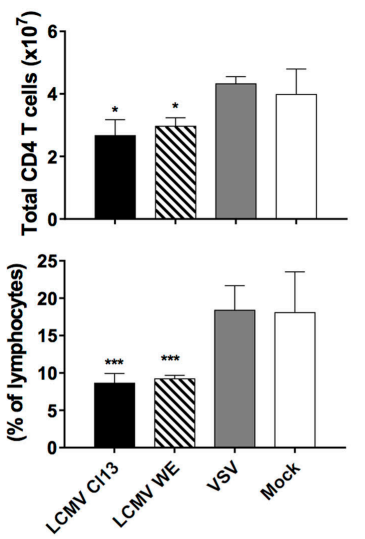

C

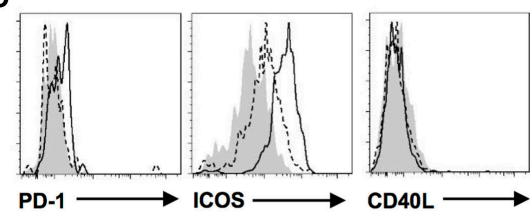

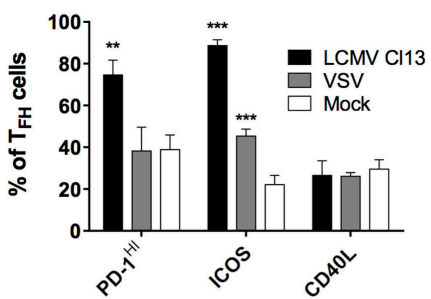
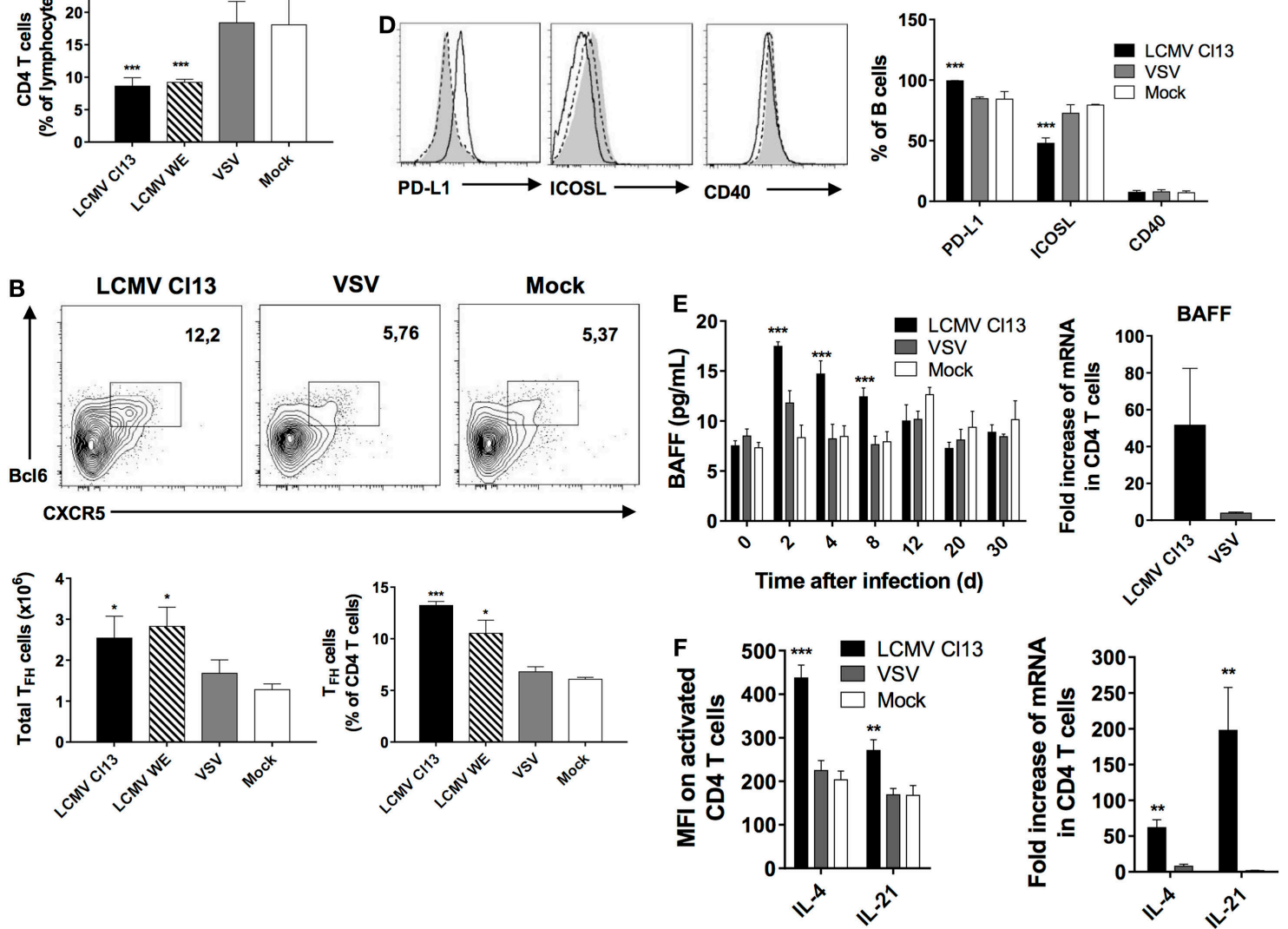

G

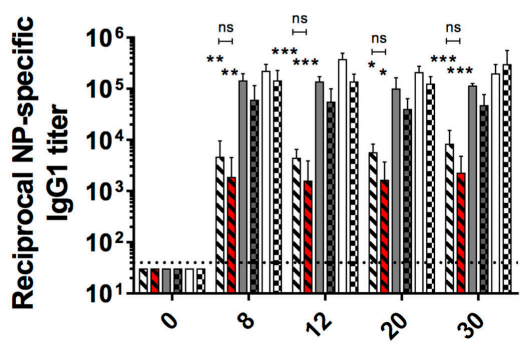

Time after immunization (d)

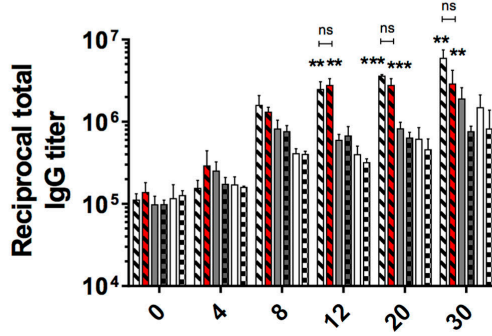

N LCMV WE

N LCMV WE $+\alpha-P D-1$

$\square$ VSV

8 VSV $+\alpha-P D-1$

$\square$ Mock

8 Mock $+\alpha-P D-1$

FIGURE 3 | LCMV infection triggers the expansion of $\mathbf{T}_{\mathrm{FH}}$ cells and induces their expression of $\mathrm{B}$ cell-activating cytokines. B6 mice (four per group) were infected with LCMV Cl13 (black bars or lines), LCMV WE (hatched), VSV (gray bars or dotted lines), or mock infected (white bars or shaded area). Mice were immunized the same day with an i.p. injection of $\mathrm{NP}_{53}-\mathrm{CGG}$ in alum and $\mathrm{CD} 4^{+} \mathrm{T}$ cells were analyzed on $\mathrm{d} 8$ after infection. (A) Total $\mathrm{CD} 4^{+} \mathrm{T}$ cell numbers (top panel) and proportions (bottom panel) determined by flow cytometry. (B) $\mathrm{T}_{\mathrm{FH}}$ cell numbers and proportions determined by flow cytometry. (C) Proportion of $T_{F H}$ cells expressing PD-1, ICOS, and CD4OL and (D) B cells expressing PD-L1, ICOSL, and CD40 determined by flow cytometry. (E) Serum BAFF concentration (left panel) and BAFF mRNA expression in total splenic CD4 T cells (right panel) measured using ELISA and qRT-PCR, respectively. (F) Intracellular cytokine levels (left panel) and mRNA expression (right panel) of IL-4 and IL-21 in CD4 T cells measured using flow cytometry and qRT-PCR, respectively. (G) NP-specific IgG1 response (left panel) and total IgG response (right panel) monitored upon infection with LCMV WE (hatched bars), VSV (gray), or mock-infected (white) infection along with injection of PD1-blocking Ab (red hatched or checkered bars). Statistical analysis was performed by individual $T$-tests between experimental groups and the mock-infected group and between non-treated and anti-PD1 Ab-treated LCMV-infected groups when indicated with brackets. ${ }^{*} p<0.05$, ${ }^{* *} p<0.01$, and ${ }^{* \star *} p<0.001$. (A,B) Representative of four independent experiments. (C-E,G) Representative of two independent experiments. (F) Representative of three independent experiments 


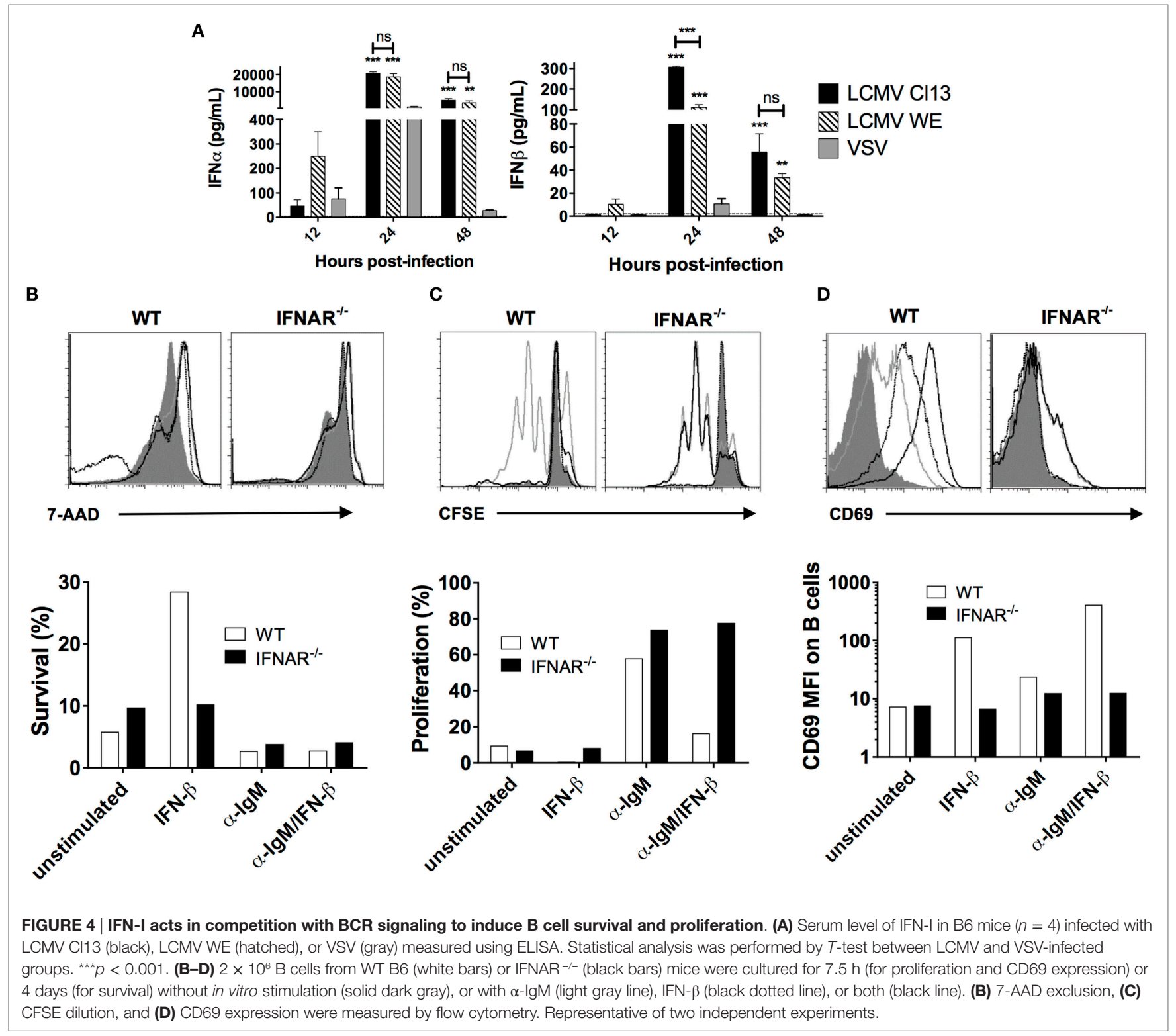

\section{IFNAR Signaling Is Essential for LCMV-Mediated Humoral Immune Response Disruption}

Previous studies have demonstrated a rapid and robust increase in LCMV-induced IFN-I levels in the serum $(16,17)$, which, as illustrated in Figure 4A, was also observed in our LCMV cohorts as well as in VSV-infected mice albeit to a much lesser extent and for a shorter duration. Next, we performed in vitro stimulation of B cells with IFN- $\beta$ in the presence or absence of BCR signaling to evaluate any modifications in survival and proliferation. Here, B cell samples were harvested from both wild-type B6 and IFNAR $^{-/}$mice to determine specific action by IFN-I. As shown in Figure 4B and consistent with a previous study (24), addition of IFN- $\beta$ in the WT B cell culture sustained B cell survival by fivefold after 4 days, whereas $\mathrm{B}$ cells from $\mathrm{IFNAR}^{-/-}$mice did not respond to IFN- $\beta$, as expected. Of note, IFN-I stimulation in this setting is likely equivalent to acute infection and our results are in agreement with the impact of IFN-I on B cells as shown in previous reports $(23,25,27-29)$. Interestingly, upon stimulation through the BCR, survival of cultured B cells was diminished regardless of addition of IFN- $\beta$. Furthermore, while BCR stimulation increased $\mathrm{B}$ cell proliferation, the addition of IFN- $\beta$ completely abrogated the BCR-dependent increase in proliferation (Figure 4C). We also measured B cell activation by evaluating expression of the activation marker CD69 upon which we found that IFN- $\beta$ increases $B$ cell activation independently of BCR stimulation (Figure 4D). Given the enhancement of survival independent and antagonistically to BCR signaling, these results suggest that IFN-I signaling could potentiate the increase of non-specific B cells while impairing the development of antigen-specific B cell responses. 
To directly evaluate the effect of IFN-I signaling on the humoral response in our in vivo model, we performed LCMV Cl13 infection and co-immunization with NP in mice that were treated with either IFNAR blocking or isotype control Abs. Although IFNAR blockade prior to LCMV Cl13 infection has been shown to enhance viral clearance in a CD4 T cell-dependent manner $(16,17)$, its impact on the Ab response during the progression of a chronic infection has not been thoroughly assessed. As depicted in Figure 5A, LCMV-specific-binding Ab responses were not significantly affected by IFNAR blockade as observed in previous reports $(16,17)$. Remarkably, however, NP-specific serum IgG1 titers were restored to levels present in VSV- or mock-infected animals upon IFNAR blockade (Figure 5B). In addition, restoration of the anti-NP IgG1 response was observed following either: a single anti-IFNAR administration conducted on $\mathrm{d}-1$ prior to the infection/immunization (Figure $5 \mathrm{C}$ ) or a series of 11 anti-IFNAR treatments conducted every third day until d30 postinfection/immunization (Figure 5D). Despite this result, it is important to note that the effect of the short-term $\mathrm{Ab}$ treatment regimens seemingly waned over time (Figures 5B,C). IFN-I has been shown to induce CSR primarily toward an IgG2a/c subtype (27). To ascertain that the LCMV-associated depletion of NP-IgG1 responses was not solely due to the skew toward NP-specific IgG2c responses, we assessed whether the recovery of NP-specific IgG1, upon IFNAR blockade, was inversely related to $\operatorname{IgG} 2 \mathrm{c}$ titers in our experimental cohorts. As shown in Figure 5E, although low-level NP-specific IgG2c titers were detected starting on $\mathrm{d} 12$ following immunization in LCMV-infected mice compared to the mock-infected group, similar levels were also observed in the VSV-infected group indicating a general effect driven by viral infection. Expectedly, IFNAR blockade reduced NP-specific IgG2c titers in LCMVinfected mice denoting a role for IFN-I in the observed CSR to IgG2c. These results indicate that, the IFN-I response generally elicited during all viral infection induces CSR to IgG2c of some antigen-specific B cells, and this effect is unlikely limited to LCMV infection or more broadly, persistent infections; thus, neither the diminished NP-specific IgG1 Ab response observed during LCMV infection nor its recovery upon IFNAR blockade is accounted for by a skewing toward or away from IgG2c responses. Altogether, these results affirm that the suppressive effect observed on the NP-specific IgG1 response during LCMV infection is dependent on IFN-I signaling and independent of CSR to IgG2c. Finally, consistent with a previous report that showed the induction of $\mathrm{HGG}$ in $\mathrm{IFNAR}^{-/}$mice following LCMV infection (38), HGG was unchanged by any of the IFNAR blockade regimen (Figures $\mathbf{5 F}-\mathbf{H}$ ).

We next evaluated the impact of IFNAR blockade on the TD $B$ cell response during LCMV infection. Consistent with the normalized IgG1 response against NP, the number of NP-specific IgG-secreting cells returned to that found in VSV- or mockinfected animals (Figure 6A, right panel) upon IFNAR blockade while total IgG-secreting cells remained elevated (Figure 6A, left panel), in agreement with sustained HGG. Surprisingly, although IFNAR blockade led to the restoration of total splenic CD4+ T cell proportions (Figure 6B), the increase in $\mathrm{T}_{\mathrm{FH}}$ observed following LCMV infection remained unchanged
(Figure 6C). Moreover, the treatment bore limited impact on IL-4 and IL-21 expression in CD4 T cells (Figure 6D), GC $\mathrm{B}$ cell proportions (Figure $6 \mathrm{E}$ ), and relative $\mathrm{Ab}$ secretion by ASCs (Figure 6F). However, relative to the isotype control, anti-IFNAR treatment resulted in moderate modulation in the expression levels of PD-L1, ICOSL, and ICOS (Figures 6G, H). As observed, $\mathrm{T}_{\mathrm{FH}}$ and GC $\mathrm{B}$ cell populations remained elevated upon IFNAR blockade despite the recovery of NP-specific Abs. Next, we sought to determine whether the structure of B cell follicles was restored upon IFNAR blockade similar to the rescue of lymphoid architecture as described in previous reports (16, $17,20)$. Here, we observed that only incomplete recovery of the $\mathrm{B}$ cell follicle structure occurred suggesting that LCMV infection induces disruption of B cell localization in a partially IFNAR-independent manner (Figure 6I). Based on the role of CXCR4 in the trafficking of B cells in lymphoid follicles and resultantly their structure (44), we examined its expression level upon IFNAR blockade. As shown in Figure 6J, left panel, we observed a remarkable elevation in CXCR4 expression in total B cells, which was restored to base levels upon IFNAR blockade. Surprisingly however, this increase in CXCR4 expression levels was not observed in the GC compartment in the LCMV-infected group compared to VSV- or mock-infected animals (Figure 6J, right panel). Nonetheless, IFNAR blockade also significantly reduced CXCR4 expression in GC B cells. These results illustrate a significant role played by IFN-I produced during LCMV infection in altering CXCR4 expression and consequently the trafficking and localization of B cells outside of follicular structures. This interplay suggests a mechanistic outline by which IFN-I modulates the humoral immune response.

\section{B Cell-Intrinsic IFN-I Signaling Directly Disrupts the Antigen-Specific Humoral Response}

Our data so far have suggested an effect of IFN-I on B cells. Therefore, to determine the role of $\mathrm{B}$ cell-intrinsic IFN-I signaling on the impaired humoral response observed during LCMV infection, we developed a chimeric model by reconstituting irradiated $\mathrm{B} 6$ mice with a mix of bone marrow cells from B cell-deficient $\left(\mathrm{J}_{\mathrm{H}} \mathrm{T}\right)$ mice (45) and $\mathrm{IFNAR}^{-1-}$ mice. As a result, we obtained chimeras in which only the $\mathrm{B}$ cells are deficient in IFN-I signaling. Upon LCMV Cl13 infection and NP-CGG immunization of $\mathrm{J}_{\mathrm{H}} \mathrm{T} / \mathrm{IFNAR}^{-/-}$chimeras, we observed restoration of the NP-specific response to levels observed in the VSV- or mock-infected B6 mice (Figure 7A), which was consistent with the IFNAR blockade experiment. Interestingly, whereas IFNAR blockade did not ameliorate HGG, the levels of total serum IgG in LCMV Cl13-infected $\mathrm{J}_{\mathrm{H}} \mathrm{T} / \mathrm{IFNAR}^{-/-}$chimeras were significantly lower than those in WT animals and normal relative to VSV and mock-infected mice (Figure 7B). Yet, despite the normalization of humoral immune responses, $\mathrm{J}_{\mathrm{H}} \mathrm{T} / \mathrm{IFNAR}^{-/-}$mice still exhibited only partial rescue of the splenic marginal-zone and B cell follicle structures (Figure 7C). Perhaps the most significant impact observed by the absence of $B$ cell-specific IFNAR signaling was the accelerated emergence of $\mathrm{nAbs}$ in the chimeras compared to both $\mathrm{J}_{\mathrm{H}} \mathrm{T} / \mathrm{B} 6$ chimeras, 

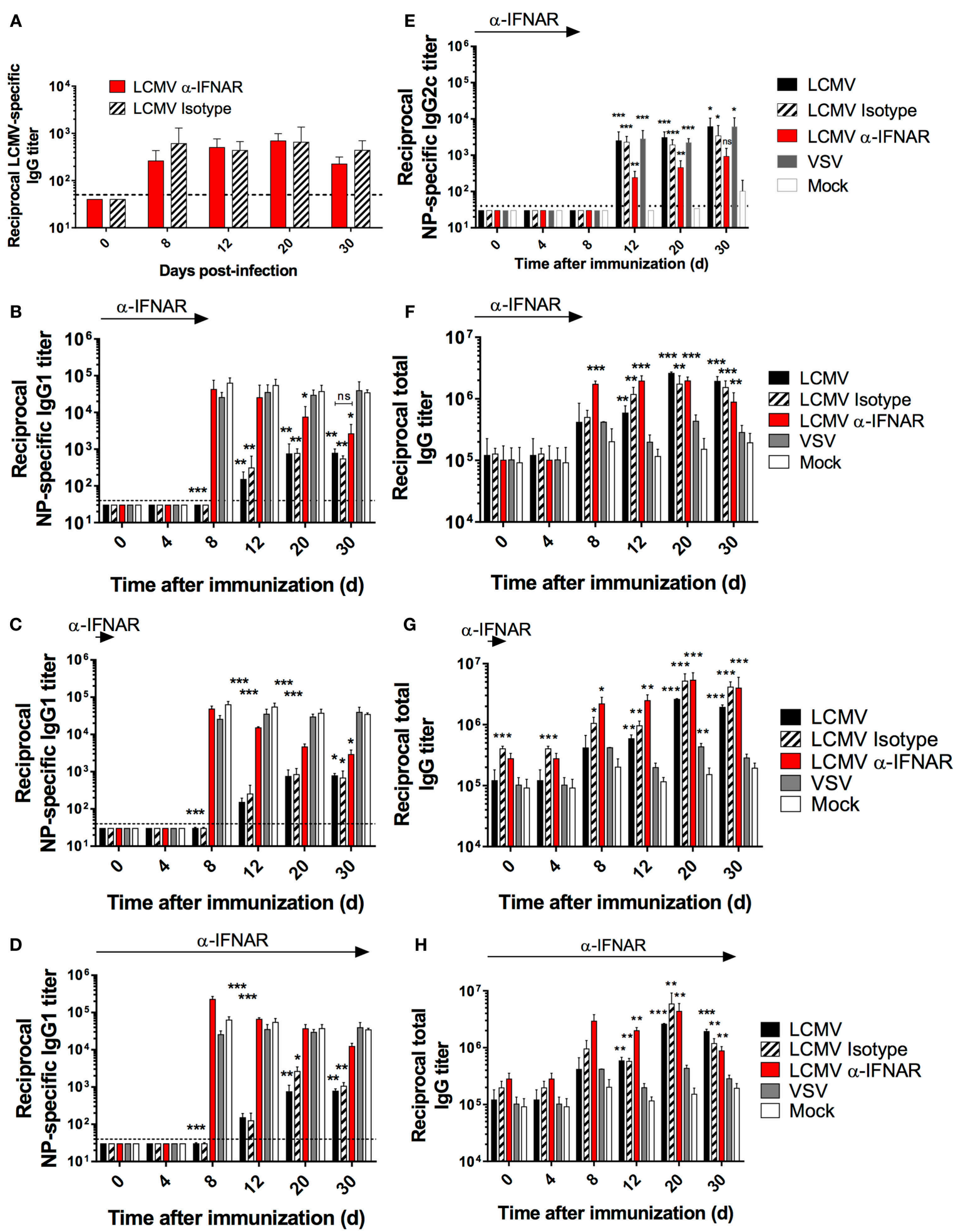

FIGURE 5 | IFNAR blockade restores NP-specific IgG1 responses during LCMV infection. B6 mice (four per group) were treated with $\alpha$-IFNAR Ab (red), isotype control $\mathrm{Ab}$ (hatched), or left untreated (black) and were infected the next day with LCMV Cl13, VSV (gray), or mock infected (white). Mice were immunized the same day with an i.p. injection of $\mathrm{NP}_{53}$-CGG in alum. (A,B,E,F) IFNAR blockade was conducted every second day until d8. In another series of experiments, anti-IFNAR treatment was stopped after either one injection (d-1) (C, G) or 11 injections every third day (d30) (D,H). (A) LCMV nucleoprotein-specific lgG titers, (B-D) NP-specific IgG1, (E) NP-specific lgG2c, (F-H) total lgG titers monitored by ELISA. Statistical analysis was performed by individual $T$-tests between experimental groups and the mock-infected group. ${ }^{*} p<0.05,{ }^{* \star} p<0.01$, and ${ }^{* \star \star} p<0.001$. The dotted line represents detection threshold. Representative of two independent experiments. 


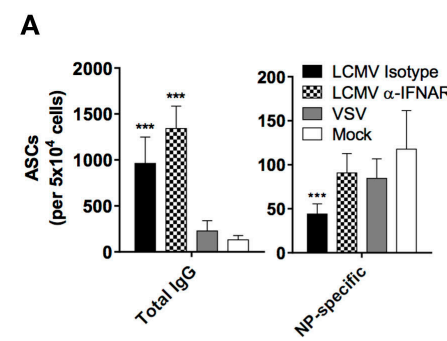

D
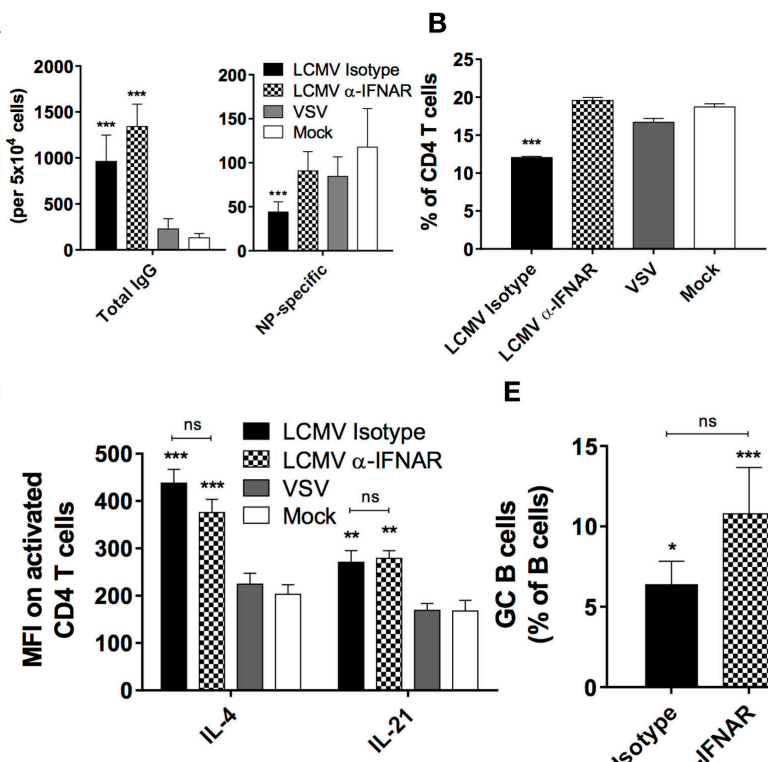

E
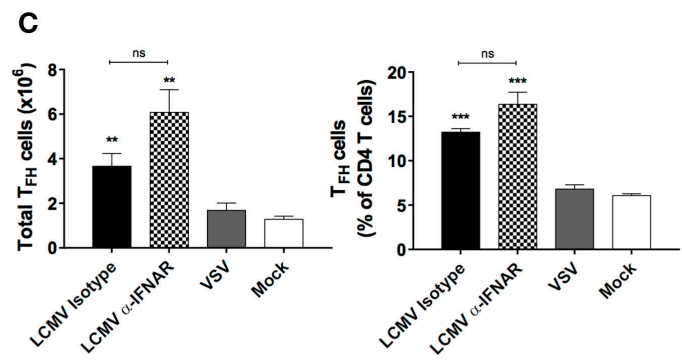

$\mathbf{F}$

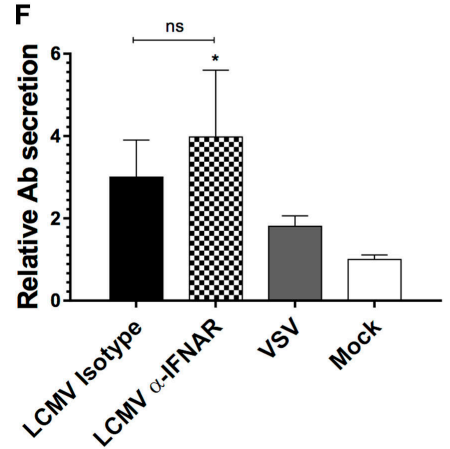

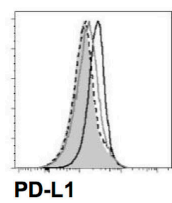
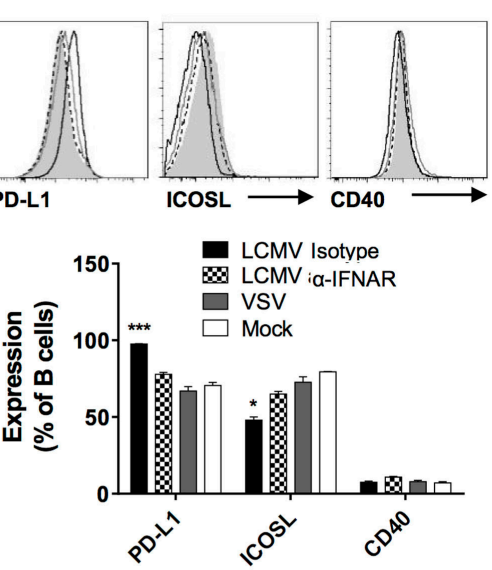

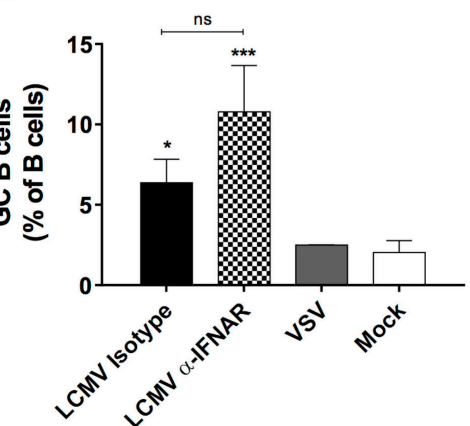

H

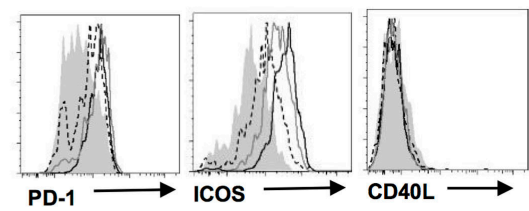

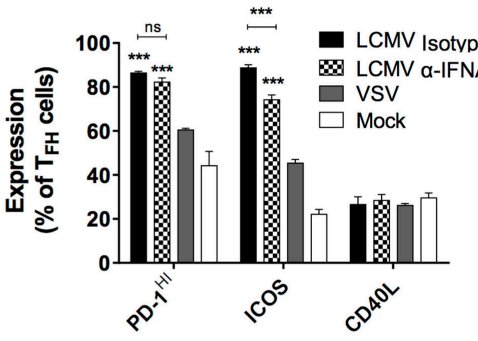
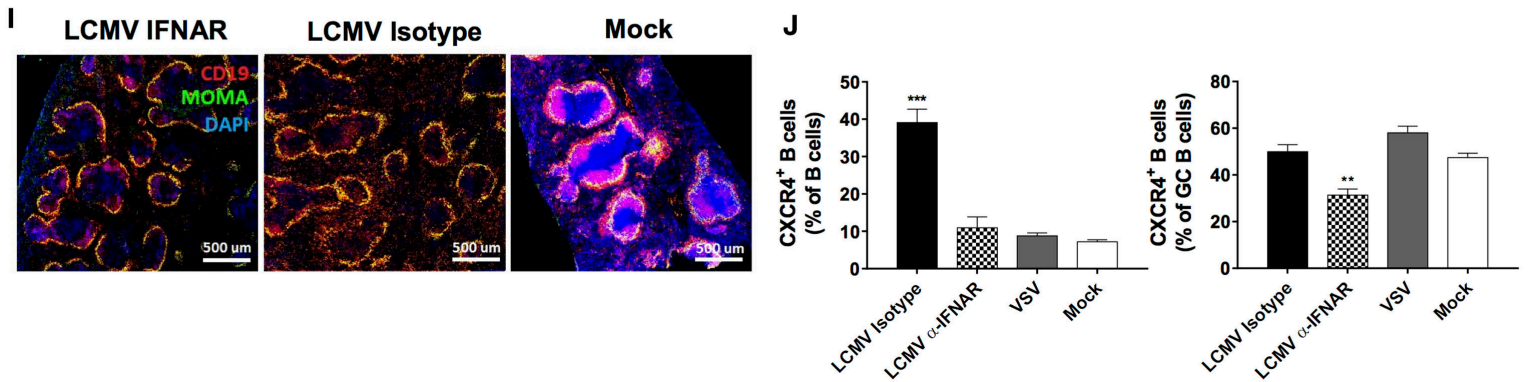

FIGURE 6 | IFNAR blockade partially restores TD B cell responses and splenic follicular structures. B6 mice (four per group) were treated with $\alpha$-IFNAR $\mathrm{Ab}$ (checkered) or isotype control Ab (black) and were infected the next day with LCMV Cl13, VSV (gray), or mock infected (white). Mice were immunized the day of the infection with an i.p. injection of $\mathrm{NP}_{53}-\mathrm{CGG}$ in alum. IFNAR blockade was conducted every second day until analysis on d8. (A) Number of total (left panel) and NP-specific IgG-secreting (right panel) cells detected by ELISPOT. (B) Proportion of CD4 T cells among total lymphocytes and (C) total numbers (left panel) and proportions (right panel) of $T_{F H}$ cells among total CD4 T cells as determined by flow cytometry. (D) Intracellular IL-4 and IL-21 levels in $T_{F H}$ cells and (E) proportion of splenic GC B cells determined by flow cytometry. (F) Secretory capacity of ASCs as determined by measuring the quantity of secreted Abs produced by $10^{5}$ splenocytes. (G) Proportion of B cells expressing PD-L1, ICOSL, and CD40. (H) Proportion of TFH cells expressing PD-1, ICOS, and CD4OL. (I) Splenic follicular structures visualized using immunofluorescent staining of CD19 (red), MOMA-1 (green), and DAPI (blue) in tissue sections. (J) Proportion of CXCR4+ B cells among total (left panel) and GC B cells (right panel) determined by flow cytometry. Statistical analysis was performed by individual $T$-tests between experimental groups and the mock-infected group and between isotype and IFNAR blocking Ab-treated groups when indicated with brackets. ${ }^{*} p<0.05,{ }^{* *} p<0.01$, and ${ }^{* *} p<0.001$. $(\mathbf{A}, \mathbf{J})$ Representative of three independent experiments. (B-I) Representative of two independent experiments. 

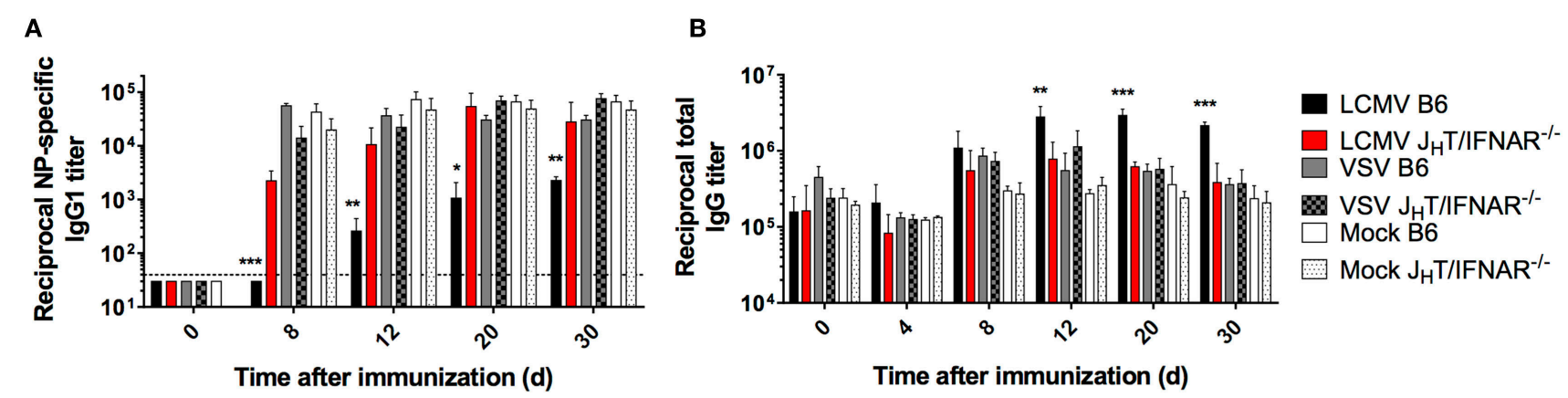

\section{C $\quad$ LCMV J $\mathrm{J}_{\mathrm{H}} \mathrm{T}^{\text {IFNAR }}{ }^{-1-}$}

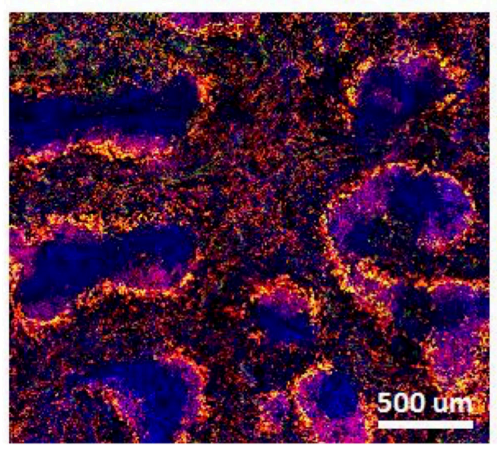

LCMV $\mathrm{J}_{\mathrm{H}} \mathrm{T} / \mathrm{B} 6$

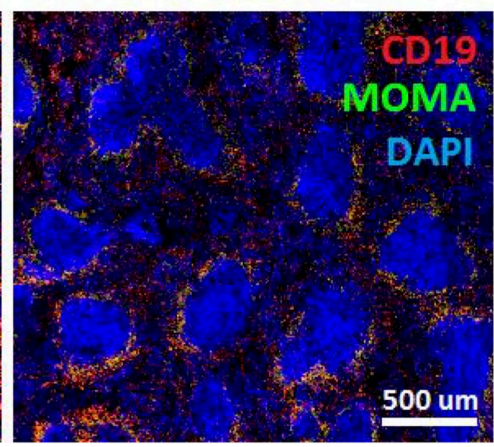

Mock

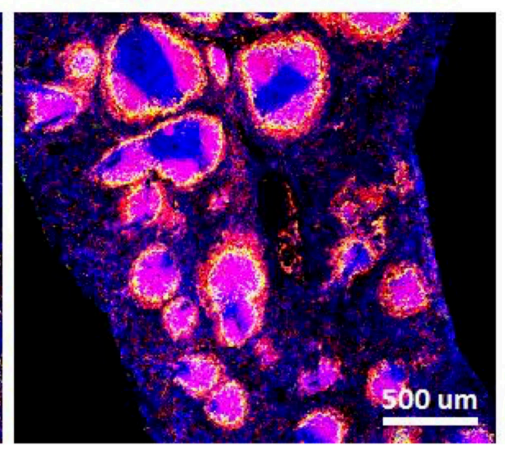

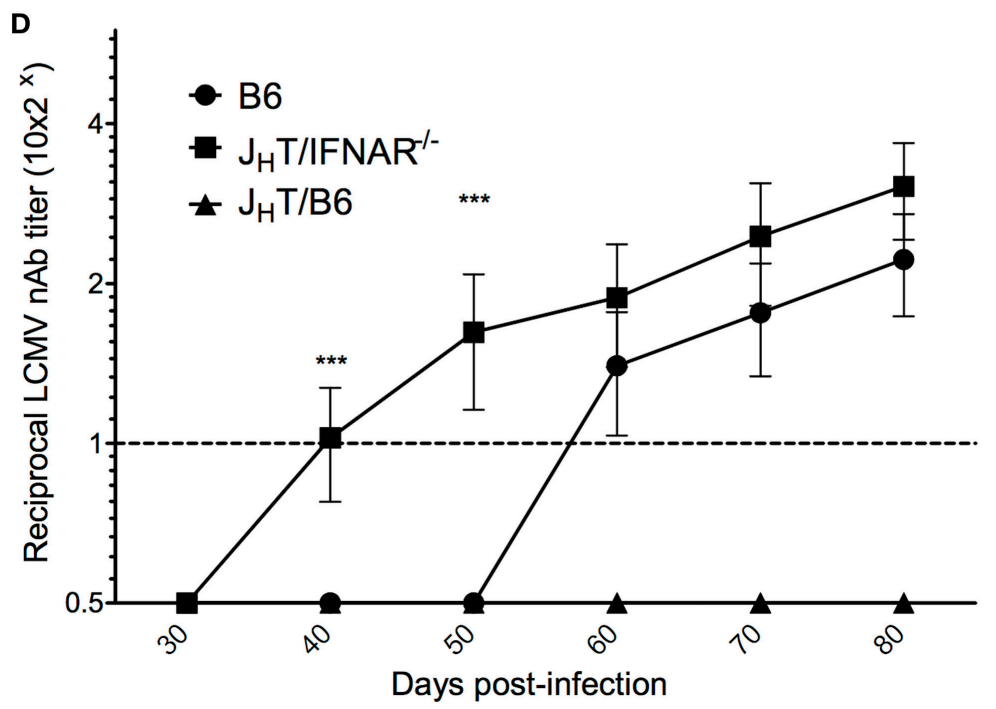

FIGURE 7 | B cell-specific disruption of IFNAR restores NP-specific Ab responses and accelerates the development of LCMV nAbs. (A-C) B6, J T/ IFNAR $^{-/-}$, or $J_{H}$ T/B6 mice (four per group) were infected with LCMV Cl13 (black for B6; red for JHT/IFNAR ${ }^{-/}$), VSV (gray), or were mock infected (white). Plain bars represent B6 mice and checkered bars $\mathrm{J}_{H} \mathrm{~T}_{/} \mathrm{IFNAR}{ }^{-/-} \mathrm{B}$ cell bone marrow chimeric mice. (A) NP-specific lgG1 and (B) total lgG responses monitored using ELISA on d8 following infection/NP ${ }_{53}-\mathrm{CGG}$ immunization. (C) Splenic follicular structures visualized using immunofluorescent staining of CD19 (red), MOMA-1 (green), and DAPI (blue) on spleen sections obtained on d8 postinfection. (D) Neutralization assay showing accelerated nAb responses in $\mathrm{J}_{H} \mathrm{~T} / \mathrm{IFNAR}{ }^{-/} \mathrm{Chimeric}_{\mathrm{mice}} \mathrm{upon}$ infection with LCMV Cl13. (A-C) Representative of two independent experiments. (D) Compilation of three independent experiments (B6 mice, $n=21$; JHT/ IFNAR $^{-/-}$mice, $n=25$; JHT/B6 mice, $n=8$ ). Statistical analysis was performed by individual $T$-tests between experimental groups and the mock-infected group for (A-C) and one-way ANOVA for (D). ${ }^{\star} p<0.05,{ }^{\star \star} p<0.01$, and ${ }^{\star \star \star} p<0.001$. The dotted line represents detection threshold.

used as controls to account for any changes driven by irradiation and reconstitution and more importantly, WT B6 mice (Figure 7D). The fact that $\mathrm{J}_{\mathrm{H}} \mathrm{T} / \mathrm{B} 6$ chimeras did not produce any detectable LCMV nAbs suggests that only partial reconstitution of the humoral response was achieved in the chimeric system. This result further underscores the significance of the accelerated $\mathrm{nAb}$ response observed in the $\mathrm{J}_{\mathrm{H}} \mathrm{T} / \mathrm{IFNAR}^{-1-}$ chimeras. Collectively, these data illustrate a potent effect borne by IFN-I 
signaling on B cells, which upon negation results in a normal NP-specific humoral response as well as enhanced induction of LCMV nAbs.

\section{DISCUSSION}

The immune response in the LCMV infection model has been classically defined as cell mediated (46) whereas the role of the humoral immune response has only been considered relevant in the context of reinfection (47). Although the absence of an initial robust $\mathrm{nAb}$ response has been primarily attributed to antiviral escape mechanisms $(32,48)$, the immunological processes that drive the disruption of humoral immunity during persistent infection are yet to be elucidated.

In this report, we reveal that emergence of humoral dysfunction during LCMV infection occurs in an IFN-I-dependent manner in which antigen specificity in the TD immune response was impaired; this effect was notably more evident in LCMV Cl13- relative to WE-infected animals. To gain deeper insight into the nature of immunological impairment, we tracked the immune response against NP rather than the actual viral antigens in different experiments to distinguish viral specific effects from global immune responses. Collectively, the presence of humoral disruption observed with both LCMV strains illustrates that pathogenic mechanisms present in the acute phase of infection as well as sustenance of viral burden in the face of prolonged LCMV Cl13 infection both play a role in the observed perturbations. However, this impairment is not a universal consequence of any viral infection or of IFN-I production per se as infection with VSV, which also promotes IFN-I production, albeit to a lesser extent than LCMV, does not lead to a disrupted humoral response; as such, LCMV-specific factors also likely play a role in the muted $\mathrm{Ab}$ response. Whereas blockade of IFN-I signaling using anti-IFNAR Abs reestablished the anti-NP response, HGG remained present consistent with a previous report in IFNAR $^{-/-}$ (38) and the expansion of the $\mathrm{T}_{\mathrm{FH}}$ and total IgG-secreting cell populations was still observed. Furthermore, the expression of costimulatory molecules between B and T cells was partially restored to levels intermediate between isotype treated and VSVinfected controls. In addition, treatment with anti-PD-1/PD-L1, which was conducted prior to infection and co-immunization, bore no impact on LCMV-mediated dysregulation. These findings along with the observed effect of IFN-I on B cell survival and proliferation in vitro suggested that LCMV-induced IFN-I acted directly on $\mathrm{B}$ cells. The significance of this interaction was demonstrated using $\mathrm{J}_{\mathrm{H}} \mathrm{T} / \mathrm{IFNAR}^{-/-}$chimeric mice in which only B cells carried the receptor knockout. Remarkably, the absence of IFN signaling on B cells restored normal humoral function with NP-specific Ab titers similar to those observed in VSV- or mock-infected mice. Moreover, B cell-specific IFNAR ablation normalized HGG consistent with a recent report in the Leishmania infection model (49). In light of the incapacity of IFNAR blockade to limit HGG, this suggests that IFN-I signaling on cells other than B cells also contributes to regulating HGG development although the exact nature of this contribution remains to be defined. Altogether, these results revealed the role of IFN-I signaling on B cells in impairing Ag-specific responses albeit possibly indirectly through the abnormal expansion of non-specific B cells.

Along with the recovery of the antigen-specific humoral response, we observed a reduction in the extent of destruction to splenic follicular architecture upon both the blockade and B cell-specific knockout of IFNAR. Similar to the recovery of the general splenic tissue organization observed in previous studies $(16,17)$, we surmise that this occurs in part due to preservation of cellular trafficking and localization in the splenic microstructure. Shuttling back and forth between the light zone (LZ) and dark zone (DZ) of the GC is actuated by differential expression of chemokine receptors such as CXCR4 and CXCR5 (50, 51). Upon analysis of CXCR4 expression on B cells, we observed that the LCMV-associated increase in total B cells was completely reversed by anti-IFNAR $\mathrm{Ab}$ administration. However, since CXCR4 expression on GC B cells was unchanged upon LCMV infection, we surmise that the overall increased expression of the chemokine receptor upon infection most likely occurred in extrafollicular B cells. It is important to note that this change to cellular trafficking and localization likely represents only a fraction of similar such changes that alter splenic structure during LCMV infection.

In addition, these changes to B cell trafficking also suggest altered positive selection thresholds of effector cells. This possibility is further advanced by the increase in GC B cell numbers as well as the expansion of the non-specific ASC population. Along with the observation of $\mathrm{T}_{\mathrm{FH}}$ increase in LCMV-infected animals, we deduce that the positive selection process in which antigen-specific B cell clones compete for survival signals from $\mathrm{T}_{\mathrm{FH}}$ is dysregulated. In this setting, the threshold for positive selection is lowered based on the aberrant expansion of $\mathrm{T}_{\mathrm{FH}}$ cells. As a result, B cells exhibiting lower antigen specificity or nonspecificity, which in the normal functional setting would not be selected, receive survival signals. Consequently, this expansion of non-specific $\mathrm{B}$ cells diminishes the likelihood of cognate $\mathrm{T}_{\mathrm{FH}}-\mathrm{B}$ cell interactions taking place in a productive manner, which leads to an impairment of specific Ab responses (see Figure 8 for proposed model). However, the affinity maturation process is still intact despite this disruption based on the stability of the high affinity $\mathrm{NP}_{4}$-BSA $\mathrm{Ab}$ titers in all the infection groups. Thus, the positive selection mechanism is functional yet stunned by the influx of non-specific B cell clones. Most significantly, the accelerated LCMV nAb response observed in the J $\mathrm{H}_{\mathrm{H}} \mathrm{IFNAR}^{-/-}$ chimeras relative to WT $\mathrm{B} 6$ and $\mathrm{J}_{\mathrm{H}} \mathrm{T} / \mathrm{B} 6$ can also be accounted for by such a mechanism. In this setting, the WT response features increased activation of non-specific B cell clones. Consequently, the response to neutralizing epitopes, which are immunorecessive, is further diminished by the effects of IFN-I signaling. This is a significant characterization given that the elicitation of $\mathrm{nAbs}$ and moreover, broadly nAbs, is also delayed in chronic infection settings such as HIV and HCV whose immunological profiles closely mirror those observed in LCMV.

Another important aspect of human persistent virus infection is poor vaccination responses in infected patients. Using NP coimmunization, our model recapitulates the diminished response against a secondary antigen and elucidates the role played by IFN-I-mediated signaling in the chronic infection setting. Other 

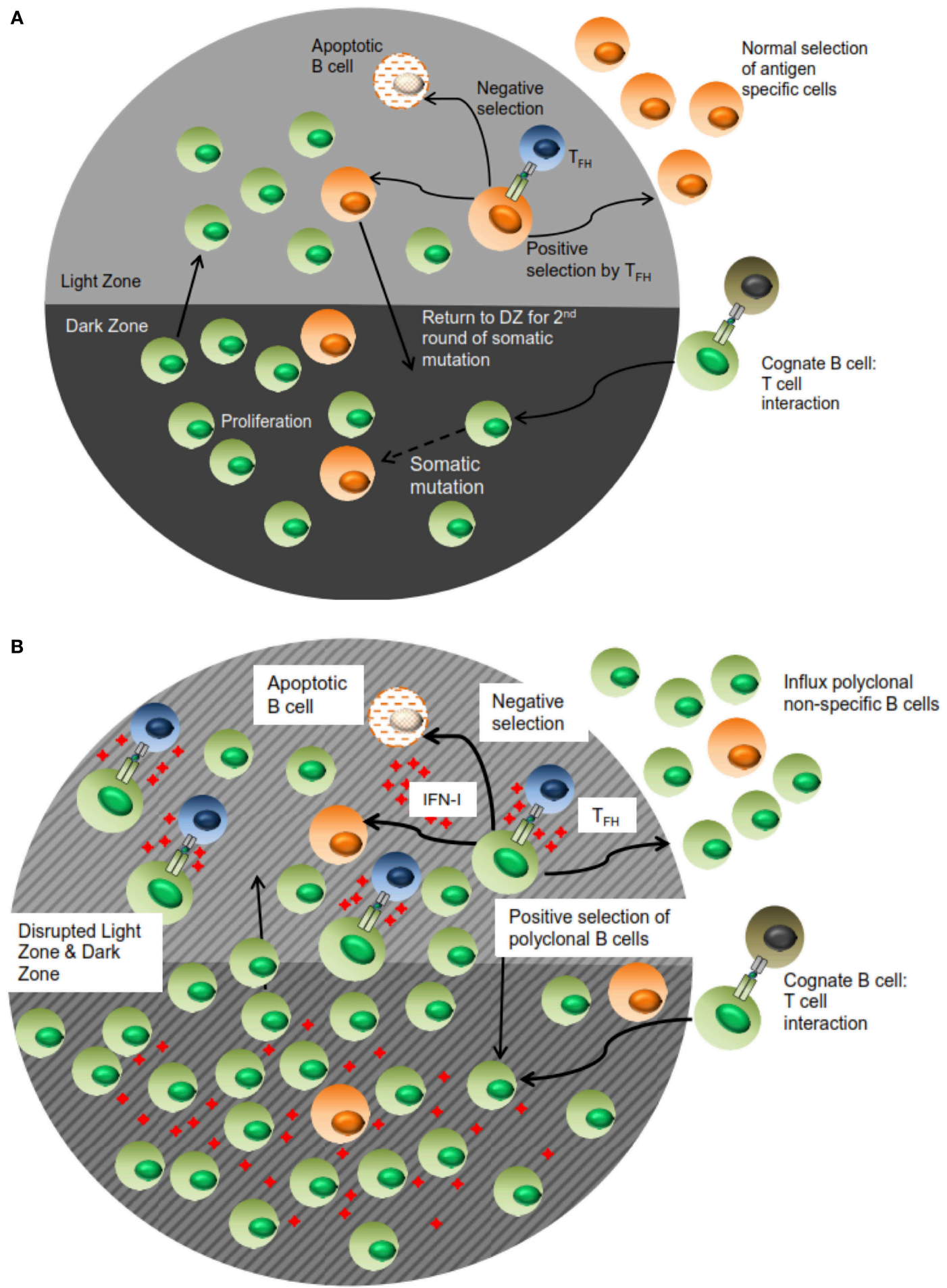

FIGURE 8 | Proposed schematic of B cell selection during a normal versus impaired humoral immune response during LCMV infection. In (A), antigen specificity of the resultant Ab response is facilitated by effective selection of B lymphocytes in the $L Z$ of the GC response. Some of these cells migrate to the periphery as effector cells while others cycle back into the DZ for proliferation in an iterative process. During LCMV and more generally, other chronic infections (B), the high concentration of IFN-I along with sustained elicitation and $T_{F H}$ expansion triggers selection of non-specific B cells in the context of a disrupted follicular architecture; as such, antigen-specific effector cells and consequently, Ab responses, are "drowned" out by the influx of non-specific cells. This figure only represents a snapshot of the process in which the immune response is further honed in (A), whereas the dilution and loss of specificity in (B) is exacerbated in subsequent rounds. 
studies have also shown that poor responses against vaccines are correlated with an increased PD-1:PD-L1 profile in HIV and HCV infected patients $(10,52)$.

In conclusion, the lack of an effective humoral immune response during LCMV infection is driven by general modulation to the humoral immune microenvironment by IFN-I. This modulation is limited to the TD response and is established early following infection; as well, blockade of IFN-I-mediated effects allows the immune response to proceed normally. Altogether, there are many aspects of the immune response to consider in their entirety, but the significance of IFN-I signaling offers an ideal anchor for future analysis and provides a therapeutic target against persistent viral infections to potentially boost $\mathrm{Ab}$ responses as well as limit immunopathogenesis.

\section{MATERIALS AND METHODS}

\section{Ethics Statement}

All animal experiments were reviewed and approved by the Institut national de la recherche scientifique (INRS) animal care committee under protocol 1302-05 and in accordance with AAALAC and Canadian Council on Animal Care (CCAC) guidelines.

\section{Mice, Infections, and Immunizations}

Six- to eight-week-old B6 female mice were purchased from Charles River Laboratories (St-Constant, QC, Canada). J T mice were obtained from Rolf M. Zinkernagel, Zurich, Switzerland. IFNAR $^{-/}$mice on a B6 background were obtained from Ulrich Kalinke, Hannover, Germany. All mice were maintained at the INRS animal facility until use.

To generate mixed bone marrow chimeric mice, bone marrow cells from 8- to 12-week-old B6, $\mathrm{J}_{\mathrm{H}} \mathrm{T}$, and IFNAR ${ }^{-1-}$ mice were mixed at a ratio of $4: 1\left(\mathrm{~J}_{\mathrm{H}} \mathrm{T} / \mathrm{IFNAR}^{-/-}\right.$or $\left.\mathrm{J}_{\mathrm{H}} \mathrm{T} / \mathrm{B} 6\right)$ and injected intravenously (i.v.) into lethally irradiated $(2 \times 600$ rads $)$ B6 mice. Mice were left untouched for $\geq 5$ weeks to allow for immune reconstitution as determined by flow cytometry.

All viral strains used in this paper were obtained from Rolf $M$. Zinkernagel, Zurich, Switzerland. Infections with LCMV Cl13, LCMV WE, or VSV Indiana were carried out by i.v. injection with $2 \times 10^{6} \mathrm{pfu}$ of virus or with culture media alone (mock).

For T cell-dependent $\mathrm{Ab}$ response characterization, mice were immunized intraperitoneally (i.p.) with $50 \mu \mathrm{g}$ alum-precipitated 4-Hydroxy-3-nitrophenylacetic hapten conjugated to CGG (NP-CGG; Biosearch Technologies, Petaluma, CA, USA), at a ratio of 53:1, or with precipitated alum alone as a control. For T cellindependent $\mathrm{Ab}$ response characterization, mice were immunized i.p. with $5 \mu \mathrm{g}$ 4-hydroxy-3-nitrophenylacetic hapten conjugated to AminoEthylCarboxyMethyl-FICOLL (NP-FICOLL; Biosearch Technologies, Petaluma, CA, USA) in PBS, at a ratio of 40:1, or with PBS alone as a control. All mice were maintained under specific pathogen-free conditions and immunizations or adoptive transfers were carried out at 6-10 weeks of age.

Blocking Abs were used to block PD-1 and IFNAR signaling. For PD-1 blockade, $250 \mu \mathrm{g}$ of blocking $\mathrm{Ab}$ or isotype control (BioXcell, West Lebanon, NH, USA) were injected i.p. every
3 days starting 1 day before infection and continuing throughout the whole experiment. For IFNAR blockade, $500 \mu \mathrm{g}$ of blocking $\mathrm{Ab}$ or isotype control (Leinco Technologies) were injected i.v. every 2-3 days starting 1 day before infection and stopping at various time points as indicated.

\section{B Cell In Vitro Stimulation and CFSE Staining}

Splenic B cells were isolated using the EasySepTM Mouse B Cell Enrichment Kit (Stemcell Technologies, Vancouver, BC, Canada) according to the manufacturer's instructions. B cells were resuspended to $2 \times 10^{7}$ cells $/ \mathrm{mL}$ in PBS containing $2 \%$ FBS and CFSE (Fisher, Waltham, MA, USA) was added to a final concentration of $1 \mu \mathrm{M}$. Samples were incubated for $5 \mathrm{~min}$ at room temperature and staining was quenched by addition of an equal amount of FBS. Cells were washed with $\mathrm{PBS} / 2 \% \mathrm{FBS}$ and resuspended in RPMI-1640 medium supplemented with 10\% FBS, $2 \mathrm{mM}$ glutamine, $100 \mathrm{U} / \mathrm{mL}$ penicillin, $100 \mu \mathrm{g} / \mathrm{mL}$ streptomycin, and $55 \mu \mathrm{M} 2$-mercaptoethanol. The $3 \times 10^{6}$ cells/well were seeded in 24-well plates and stimulated with either $10 \mu \mathrm{g} / \mathrm{mL}$ goat antimouse IgM (Jackson Immunoresearch, West Grove, PA, USA) and $500 \mathrm{U} / \mathrm{mL}$ mouse IFN- $\beta$ (Quansys Biosciences, Logan, UT, USA) or respective combinations and cultured $\left(37^{\circ} \mathrm{C}, 5 \% \mathrm{CO} 2\right)$ for either $7.5 \mathrm{~h}$ or 4 days.

\section{Antibodies and Detection Reagents}

The following staining reagents were used: anti-CD3 (145-2C11), anti-CD4 (H129.19), anti-CD62L (MEL-14), anti-CD44 (IM7), anti-CD45R (RA3-6B2), anti-PD-1 (29F.1A12), anti-PD-L1 (10F.9G2), anti-ICOSL (HK5.3), anti-CD40 (HM40-3), antiCD40L (MR1), anti-CXCR4 (L276F12), and anti-IL-4 (11b11) were from Biolegend(San Diego, CA, USA); anti-CD19 (eBio1D3), anti-ICOS (7E.17G9), anti-IL-21 (mhalx21), anti-CD69 (H1.2F3), and anti-GL7 (GL-7) were from eBiosciences (San Diego, CA, USA); anti-Bcl-6 (K112-91), anti-CXCR5 (2G8), and anti-Fas (Jo2) were from BD Biosciences (Franklin Lakes, NJ, USA). PNA (B-1075; Vector Laboratories, Burlington, ON, Canada) was used for staining germinal center B cells and MOMA-1 (Abcam, Cambridge, UK) for staining MZ macrophages.

\section{Flow Cytometry}

Single-cell suspensions of splenocytes were stained on ice with the appropriate Abs in PBS containing 1\% (v/v) bovine serum albumin (BSA, Fisher, Waltham, MA, USA) and 0.1\% (w/v) sodium azide (GE Healthcare, Mississauga, ON, Canada). Nonspecific staining was blocked by $2.4 \mathrm{G} 2 \mathrm{Ab}$ against CD16/32 [Biolegend; prepared as previously described (53)]. Samples were fixed with $1 \%(\mathrm{v} / \mathrm{v})$ paraformaldehyde and analyzed on a BD LSR II Fortessa (BD Bioscience). For intracellular cytokine staining, splenocytes were stimulated ex vivo for $5 \mathrm{~h}$ with phorbol 12-myristate 13-acetate (PMA, Sigma-Aldrich, Saint-Louis, MI, USA) (100 ng/mL), ionomycin (Sigma-Aldrich) $(1 \mu \mathrm{M})$, and Brefeldin A (Sigma-Aldrich) $(10 \mu \mathrm{g} / \mathrm{mL})$. Samples were fixed and permeabilized prior to incubation with $\mathrm{Ab}$ in permeabilization buffer (eBiosciences). Dead cells were excluded based on positive staining with 7-Amino-Actinomycin D (7-AAD) 
(BD Pharmingen), and doublets gated out using FSA-A/SSC-A. Data were analyzed with FlowJo software (TreeStar, Ashland, OR, USA).

\section{Quantitative RT-PCR}

$\mathrm{CD}^{+} \mathrm{T}$ cells were magnetically selected using the EasySep system (StemCell, Vancouver, BC, Canada), frozen, and conserved at $-80^{\circ} \mathrm{C}$. Total RNA was isolated using the RNeasy Mini kit (Qiagen, Hilden, Germany) and quantified by Nanodrop ND-1000 (Fisher, Waltham, MA, USA). cDNA was synthesized from total RNA using the Superscript III First-Strand Synthesis SuperMix (Applied Biosystems) and frozen at $-80^{\circ} \mathrm{C}$ until use. Gene expression was determined by quantitative PCR using TaqMan Gene expression System (Life Technologies, Burlington, ON, Canada) on a Rotor-gene 6000 system (Corbett, Concorde, NSW, Australia). Standard commercial TaqMan probes were used for IL-4, IL-21 and BAFF (Life Technologies). Samples were normalized to GAPDH and represented as fold change over mock-infected mice using the $\Delta \Delta \mathrm{CT}$ method (54).

\section{ELISA and ELISPOT Assay}

For NP-specific serum Ig detection, 96-well plates (Mabtech, Cincinnati, OH, USA) were coated overnight at $4^{\circ} \mathrm{C}$ with $0.1 \mu \mathrm{g}$ of NP-BSA conjugated at a ratio of NP to BSA ranging from $4: 1$ to $26: 1$. For total serum IgG detection, microtiter plates were coated overnight at $4^{\circ} \mathrm{C}$ with unlabeled anti-IgG (Jackson ImmunoResearch, West Grove, PA, USA) at $2 \mu \mathrm{g} /$ $\mathrm{mL}$. Non-specific binding was blocked with $10 \%(\mathrm{v} / \mathrm{v})$ fetal bovine serum and $0.2 \%$ (v/v) Tween 20 in PBS. Horseradish peroxidase (HRP)-conjugated secondary Abs: anti-IgM, antiIgG1, anti-IgG2c, anti-IgG3, and anti-IgG (total IgG) (Jackson ImmunoResearch, West Grove, PA, USA) were detected with $0.04 \%(\mathrm{w} / \mathrm{v})$ o-phenylenediamine and $0.8 \% \mathrm{H}_{2} \mathrm{O}_{2}(\mathrm{v} / \mathrm{v})$ in citrate buffer. Serum BAFF detection was done by coating 96 -well plates overnight at $4^{\circ} \mathrm{C}$ with $2 \mu \mathrm{g}$ of anti-BAFF $\mathrm{Ab}$ (R\&D Systems, Minneapolis, MN, USA) in carbonate buffer. Non-specific binding was blocked with $1 \%(\mathrm{v} / \mathrm{v}) \mathrm{BSA}$ in PBS. HRP-conjugated anti-BAFF secondary Ab (R\&D Systems) was detected with $0.04 \%(\mathrm{w} / \mathrm{v})$ o-phenylenediamine and $0.8 \% \mathrm{H}_{2} \mathrm{O}_{2}(\mathrm{v} / \mathrm{v})$ in citrate buffer. Serum IFN- $\alpha$ and $-\beta$ detection was done using Verikine kits (PBL Assay Science, Piscataway Township, NJ, USA) in conditions recommended by the company. LCMV nucleoproteinspecific IgG serum Abs were determined by ELISA using plates coated with purified recombinant LCMV nucleoprotein-GST as previously described (55).

For ASC determination by ELISPOT, a mouse IgG ELISPOT ${ }^{\text {Plus }}$ kit (Mabtech, Nacka Strand, Sweden) was used. Briefly, 96-well nitrocellulose plates (Millipore, Etobicoke, ON, Canada) were coated overnight at $4^{\circ} \mathrm{C}$ with anti-IgG antibody. Non-specific binding was blocked with 5\% (v/v) FBS in PBS. Cell suspensions obtained from spleens were added to wells $\left(10^{4}\right.$ cells for detection of IgG and $10^{5}$ for NP) in duplicate and incubated overnight at $37^{\circ} \mathrm{C}$ in a $5 \% \mathrm{CO}_{2}$ atmosphere. $\mathrm{B}$ cell spots were developed by sequential washes with $\mathrm{PBS}$, addition of biotinylated anti-IgG or NP-BSA-Biotin, washes with PBS, addition of streptavidinalkaline phosphatase, washes with PBS and addition of 5-Bromo4-chloro-3-indolyl phosphate substrate for $15 \mathrm{~min}$. Spots were counted using an AID Elispot Reader (Autoimmun Diagnostika GmbH, Strasberg, Germany).

\section{Immunochemistry}

Freshly harvested spleens were flash frozen in OCT (Electron Microsopy Sciences, Hartfield, PA, USA) in liquid nitrogen, stored at $-80^{\circ} \mathrm{C}$ and processed for sets of $10-\mu \mathrm{m}$ section sizes with a cryostat (Microm HM 525; GMI, Ramsey, MN, USA). Tissue sections were fixed on slides in $75 \%$ acetone and $25 \%$ ethanol (v/v) for $5 \mathrm{~min}$ and incubated with primary reagent in PBS for $1 \mathrm{~h}$ at room temperature. The following primary reagents were used: anti-mouse CD19-PE (RA3-6B2, eBiosciences, 1:10000) and anti-mouse MOMA-1-FITC (Abcam, Toronto, ON, Canada, 1:200). Tissue sections were then washed in PBS and incubated with a secondary Alexa 488 anti-FITC (Life Technologies) to amplify FITC signal or strep-A488 if needed. Tissue sections were then mounted with Prolong (Life Technologies), dried overnight, and observed using a LSM780 confocal microscope (Carl Zeiss, Oberkochen, Germany).

\section{Ab Secretion Quantification}

Freshly prepared splenocyte suspensions were plated in triplicates in 96-well flat bottom plates at $10^{5}$ cells per well in culture medium containing DMEM, 10\% FBS, 1\% streptavidin/penicillin, 1\% L-glutamine, $1 \%$ sodium pyruvate, and $\beta$-mercaptoethanol. Cells were incubated for $48 \mathrm{~h}$ at $37^{\circ} \mathrm{C}$ and culture media was harvested to quantify $\mathrm{Ab}$ by ELISA. This quantitation was compared to the numeration of ASCs obtained using ELISPOT to define an individual secretion per ASC cell.

\section{LCMV nAb Quantification}

Lymphocytic choriomeningitis virus nAbs were quantified as described previously (56). In brief, serial 2-fold dilutions of 10 -fold prediluted sera were incubated with LCMV for $90 \mathrm{~min}$ at $37^{\circ} \mathrm{C}$ in 96 -well plates. MC57G mouse fibroblasts were added and incubated for $1 \mathrm{~h}$ to allow cells to settle and be infected by non-neutralized virus; cells were then overlaid with $1 \%$ methylcellulose in MEM. After $48 \mathrm{~h}$, cell monolayers were fixed with $4 \%$ formalin and infectious foci were detected by intracellular LCMV staining of infected cells with rat anti-LCMV mAb VL-4.

\section{Statistical Analysis}

Data were analyzed using Prism 6 (GraphPad Software, Inc.). Statistical significance was assessed as indicated using unpaired two-sided T-test, or a one-way ANOVA with Tukey's multiple comparisons test. $p$ Value $<0.05$ was considered significant. ${ }^{*} p<0.05,{ }^{* *} p<0.01$, and ${ }^{* * *} p<0.001$. Data are represented as means $\pm \mathrm{SD}$.

\section{AUTHOR CONTRIBUTIONS}

MD and AM designed and performed experiments, analyzed data, and wrote the paper; BM designed and performed experiments and analyzed data; AG and ET performed experiments; PL helped to analyze data; JF designed parts of the study and analyzed data; AL directed the study, analyzed data and organized, designed, and wrote the paper. 


\section{ACKNOWLEDGMENTS}

The authors thank S. Moir and J. Van Grevenynghe for helpful discussions and critical review of the manuscript.

\section{FUNDING}

This work was supported by the Canadian Institutes of Health Research (CIHR), grant MOP-89797, the Natural Sciences and Engineering Research Council of Canada, grant 3559792013, and the Jeanne and J.-Louis Lévesque Research Chair in Immunovirology from the J.-Louis Lévesque Foundation (AL); CIHR grant MOP-114972 and Canadian Foundation of Innovation Leaders Opportunity Fund infrastructure grant (JF).

\section{REFERENCES}

1. Murira A, Lapierre P, Lamarre A. Evolution of the humoral response during $\mathrm{HCV}$ infection: theories on the origin of broadly neutralizing antibodies and implications for vaccine design. Adv Immunol (2016) 129:55-107. doi:10.1016/bs.ai.2015.09.004

2. Charles ED, Green RM, Marukian S, Talal AH, Lake-Bakaar GV, Jacobson $\mathrm{IM}$, et al. Clonal expansion of immunoglobulin $\mathrm{M}+\mathrm{CD} 27+\mathrm{B}$ cells in HCV-associated mixed cryoglobulinemia. Blood (2008) 111(3):1344-56. doi:10.1182/blood-2007-07-101717

3. Moir S, Ho J, Malaspina A, Wang W, DiPoto AC, O'Shea MA, et al. Evidence for HIV-associated B cell exhaustion in a dysfunctional memory B cell compartment in HIV-infected viremic individuals. J Exp Med (2008) 205(8):1797-805. doi:10.1084/jem.20072683

4. De Milito A, Nilsson A, Titanji K, Thorstensson R, Reizenstein E, Narita M, et al. Mechanisms of hypergammaglobulinemia and impaired antigen-specific humoral immunity in HIV-1 infection. Blood (2004) 103(6):2180-6. doi:10.1182/blood-2003-07-2375

5. Racanelli V, Frassanito MA, Leone P, Galiano M, De Re V, Silvestris F, et al. Antibody production and in vitro behavior of CD27-defined B-cell subsets: persistent hepatitis C virus infection changes the rules. J Virol (2006) 80(8):3923-34. doi:10.1128/JVI.80.8.3923-3934.2006

6. He B, Qiao X, Klasse PJ, Chiu A, Chadburn A, Knowles DM, et al. HIV-1 envelope triggers polyclonal Ig class switch recombination through a CD40-independent mechanism involving BAFF and C-type lectin receptors. J Immunol (2006) 176(7):3931-41. doi:10.4049/jimmunol.176.7.3931

7. Qiao X, He B, Chiu A, Knowles DM, Chadburn A, Cerutti A. Human immunodeficiency virus $1 \mathrm{Nef}$ suppresses CD40-dependent immunoglobulin class switching in bystander B cells. Nat Immunol (2006) 7(3):302-10. doi:10.1038/ ni1302

8. Pallikkuth S, Parmigiani A, Silva SY, George VK, Fischl M, Pahwa R, et al. Impaired peripheral blood T-follicular helper cell function in HIV-infected nonresponders to the $2009 \mathrm{H1N1} / 09$ vaccine. Blood (2012) 120(5):985-93. doi:10.1182/blood-2011-12-396648

9. Moir S, Fauci AS. Insights into B cells and HIV-specific B-cell responses in HIV-infected individuals. Immunol Rev (2013) 254(1):207-24. doi:10.1111/ imr.12067

10. Cubas RA, Mudd JC, Savoye AL, Perreau M, van Grevenynghe J, Metcalf T, et al. Inadequate $\mathrm{T}$ follicular cell help impairs B cell immunity during HIV infection. Nat Med (2013) 19(4):494-9. doi:10.1038/nm.3109

11. Feng J, Hu X, Guo H, Sun X, Wang J, Xu L, et al. Patients with chronic hepatitis $\mathrm{C}$ express a high percentage of CD4(+)CXCR5(+) $\mathrm{T}$ follicular helper cells. J Gastroenterol (2012) 47(9):1048-56. doi:10.1007/s00535-0120568-1

12. Fahey LM, Wilson EB, Elsaesser H, Fistonich CD, McGavern DB, Brooks DG. Viral persistence redirects CD4 $\mathrm{T}$ cell differentiation toward $\mathrm{T}$ follicular helper cells. J Exp Med (2011) 208(5):987-99. doi:10.1084/jem. 20101773

\section{SUPPLEMENTARY MATERIAL}

The Supplementary Material for this article can be found online at http://journal.frontiersin.org/article/10.3389/fimmu.2016.00564/ full\#supplementary-material.

FIGURE S1 | Kinetics of the LCMV WE-dependent impairment of the NP-specific Ab response. B6 mice (four per group) were infected with LCMV WE (black), VSV Ind (gray), or mock infected (white). Mice were then immunized with an i.p. injection of $\mathrm{NP}_{53}-\mathrm{CGG}$ in alum following a varying immunization schedule (from d-4 to d30). (A) NP-specific IgG1 response in each differentially timed experiment monitored by ELISA. (B) ELISA plates were coated with $\mathrm{NP}_{4}-\mathrm{BSA}$ or $\mathrm{NP}_{26}-\mathrm{BSA}$ and high affinity $\mathrm{Ab}$ responses were measured as a ratio of Abs binding to $\mathrm{NP}_{4}$-BSA versus the total anti-NP lgG1 response binding to $\mathrm{NP}_{26}$-BSA in each differentially timed experiment. Statistical analysis was performed by individual $T$-tests between experimental groups and the mock-infected group. ${ }^{*} p<0.05,{ }^{\star *} p<0.01$, and ${ }^{\star \star *} p<0.001$.

13. Osokine I, Snell LM, Cunningham CR, Yamada DH, Wilson EB, Elsaesser HJ, et al. Type I interferon suppresses de novo virus-specific CD4 Th1 immunity during an established persistent viral infection. Proc Natl Acad Sci U S A (2014) 111(20):7409-14. doi:10.1073/pnas.1401662111

14. McNab F, Mayer-Barber K, Sher A, Wack A, O'Garra A. Type I interferons in infectious disease. Nat Rev Immunol (2015) 15(2):87-103. doi:10.1038/ nri3787

15. Oldstone MB. A Jekyll and Hyde profile: type 1 interferon signaling plays a prominent role in the initiation and maintenance of a persistent virus infection. J Infect Dis (2015) 212(Suppl 1):S31-6. doi:10.1093/infdis/jiu501

16. Teijaro JR, Ng C, Lee AM, Sullivan BM, Sheehan KC, Welch M, et al. Persistent LCMV infection is controlled by blockade of type I interferon signaling. Science (2013) 340(6129):207-11. doi:10.1126/science.1235214

17. Wilson EB, Yamada DH, Elsaesser H, Herskovitz J, Deng J, Cheng G, et al. Blockade of chronic type I interferon signaling to control persistent LCMV infection. Science (2013) 340(6129):202-7. doi:10.1126/science.1235208

18. Barber DL, Wherry EJ, Masopust D, Zhu B, Allison JP, Sharpe AH, et al. Restoring function in exhausted CD8 T cells during chronic viral infection. Nature (2006) 439(7077):682-7. doi:10.1038/nature04444

19. Brooks DG, Trifilo MJ, Edelmann KH, Teyton L, McGavern DB, Oldstone MB. Interleukin-10 determines viral clearance or persistence in vivo. Nat Med (2006) 12(11):1301-9. doi:10.1038/nm1492

20. Ng CT, Sullivan BM, Teijaro JR, Lee AM, Welch M, Rice S, et al. Blockade of interferon beta, but not interferon alpha, signaling controls persistent viral infection. Cell Host Microbe (2015) 17(5):653-61. doi:10.1016/j. chom.2015.04.005

21. Wilson EB, Kidani Y, Elsaesser H, Barnard J, Raff L, Karp CL, et al. Emergence of distinct multiarmed immunoregulatory antigen-presenting cells during persistent viral infection. Cell Host Microbe (2012) 11(5):481-91. doi:10.1016/j. chom.2012.03.009

22. Coro ES, Chang WL, Baumgarth N. Type I IFN receptor signals directly stimulate local B cells early following influenza virus infection. J Immunol (2006) 176(7):4343-51. doi:10.4049/jimmunol.176.7.4343

23. Le Bon A, Schiavoni G, D’Agostino G, Gresser I, Belardelli F, Tough DF. Type I interferons potently enhance humoral immunity and can promote isotype switching by stimulating dendritic cells in vivo. Immunity (2001) 14(4):461-70. doi:10.1016/S1074-7613(01)00126-1

24. Braun D, Caramalho I, Demengeot J. IFN-alpha/beta enhances BCRdependent B cell responses. Int Immunol (2002) 14(4):411-9. doi:10.1093/ intimm/14.4.411

25. Fink K, Lang KS, Manjarrez-Orduno N, Junt T, Senn BM, Holdener M, et al. Early type I interferon-mediated signals on B cells specifically enhance antiviral humoral responses. Eur J Immunol (2006) 36(8):2094-105. doi:10.1002/ eji.200635993

26. Jego G, Palucka AK, Blanck JP, Chalouni C, Pascual V, Banchereau J. Plasmacytoid dendritic cells induce plasma cell differentiation through type I interferon and interleukin 6. Immunity (2003) 19(2):225-34. doi:10.1016/ S1074-7613(03)00208-5 
27. Swanson CL, Wilson TJ, Strauch P, Colonna M, Pelanda R, Torres RM. Type I IFN enhances follicular B cell contribution to the T cell-independent antibody response. JExp Med (2010) 207(7):1485-500. doi:10.1084/jem. 20092695

28. Bach P, Kamphuis E, Odermatt B, Sutter G, Buchholz CJ, Kalinke U. Vesicular stomatitis virus glycoprotein displaying retrovirus-like particles induce a type I IFN receptor-dependent switch to neutralizing IgG antibodies. J Immunol (2007) 178(9):5839-47. doi:10.4049/jimmunol.178.9.5839

29. Zhu J, Huang X, Yang Y. Type I IFN signaling on both B and CD4 T cells is required for protective antibody response to adenovirus. J Immunol (2007) 178(6):3505-10. doi:10.4049/jimmunol.178.6.3505

30. Moir S, Malaspina A, Pickeral OK, Donoghue ET, Vasquez J, Miller NJ, et al. Decreased survival of B cells of HIV-viremic patients mediated by altered expression of receptors of the TNF superfamily. J Exp Med (2004) 200(7):587-99. doi:10.1084/jem.20032236

31. Battegay M, Moskophidis D, Waldner H, Brundler MA, Fung-Leung WP, Mak TW, et al. Impairment and delay of neutralizing antiviral antibody responses by virus-specific cytotoxic T cells. J Immunol (1993) 151(10): 5408-15.

32. Pinschewer DD, Perez M, Jeetendra E, Bachi T, Horvath E, Hengartner H, et al. Kinetics of protective antibodies are determined by the viral surface antigen. J Clin Invest (2004) 114(7):988-93. doi:10.1172/JCI200422374

33. Ciurea A, Hunziker L, Klenerman P, Hengartner H, Zinkernagel RM. Impairment of $\mathrm{CD} 4(+) \mathrm{T}$ cell responses during chronic virus infection prevents neutralizing antibody responses against virus escape mutants. J Exp Med (2001) 193(3):297-305. doi:10.1084/jem.193.3.297

34. Fung-Leung WP, Kundig TM, Zinkernagel RM, Mak TW. Immune response against lymphocytic choriomeningitis virus infection in mice without CD8 expression. J Exp Med (1991) 174(6):1425-9. doi:10.1084/jem.174.6.1425

35. Moskophidis D, Cobbold SP, Waldmann H, Lehmann-Grube F. Mechanism of recovery from acute virus infection: treatment of lymphocytic choriomeningitis virus-infected mice with monoclonal antibodies reveals that Lyt-2+ T lymphocytes mediate clearance of virus and regulate the antiviral antibody response. J Virol (1987) 61(6):1867-74.

36. Steinhoff U, Muller U, Schertler A, Hengartner H, Aguet M, Zinkernagel RM. Antiviral protection by vesicular stomatitis virus-specific antibodies in alpha/ beta interferon receptor-deficient mice. J Virol (1995) 69(4):2153-8.

37. Cumano A, Rajewsky K. Structure of primary anti-(4-hydroxy-3-nitrophenyl) acetyl (NP) antibodies in normal and idiotypically suppressed C57BL/6 mice. Eur J Immunol (1985) 15(5):512-20. doi:10.1002/eji.1830150517

38. Hunziker L, Recher M, Macpherson AJ, Ciurea A, Freigang S, Hengartner H, et al. Hypergammaglobulinemia and autoantibody induction mechanisms in viral infections. Nat Immunol (2003) 4(4):343-9. doi:10.1038/ni911

39. Kawamoto H, Sakaguchi K, Takaki A, Ogawa S, Tsuji T. Autoimmune responses as assessed by hypergammaglobulinemia and the presence of autoantibodies in patients with chronic hepatitis C. Acta Med Okayama (1993) 47(5):305-10

40. Odermatt B, Eppler M, Leist TP, Hengartner H, Zinkernagel RM. Virustriggered acquired immunodeficiency by cytotoxic T-cell-dependent destruction of antigen-presenting cells and lymph follicle structure. Proc Natl Acad Sci U S A (1991) 88(18):8252-6. doi:10.1073/pnas.88.18.8252

41. Hatzi K, Nance JP, Kroenke MA, Bothwell M, Haddad EK, Melnick A, et al. BCL6 orchestrates Tfh cell differentiation via multiple distinct mechanisms. J Exp Med (2015) 212(4):539-53. doi:10.1084/jem.20141380

42. Good-Jacobson KL, Szumilas CG, Chen L, Sharpe AH, Tomayko MM, Shlomchik MJ. PD-1 regulates germinal center B cell survival and the formation and affinity of long-lived plasma cells. Nat Immunol (2010) 11(6):535-42. doi: $10.1038 /$ ni. 1877

43. Frebel H, Nindl V, Schuepbach RA, Braunschweiler T, Richter K, Vogel J, et al. Programmed death 1 protects from fatal circulatory failure during systemic virus infection of mice. J Exp Med (2012) 209(13):2485-99. doi:10.1084/ jem. 20121015
44. Nie Y, Waite J, Brewer F, Sunshine MJ, Littman DR, Zou YR. The role of CXCR4 in maintaining peripheral B cell compartments and humoral immunity. J Exp Med (2004) 200(9):1145-56. doi:10.1084/jem.20041185

45. Chen J, Trounstine M, Alt FW, Young F, Kurahara C, Loring JF, et al. Immunoglobulin gene rearrangement in B cell deficient mice generated by targeted deletion of the JH locus. Int Immunol (1993) 5(6):647-56. doi:10.1093/ intimm/5.6.647

46. Zinkernagel RM, LaMarre A, Ciurea A, Hunziker L, Ochsenbein AF, McCoy $\mathrm{KD}$, et al. Neutralizing antiviral antibody responses. Adv Immunol (2001) 79:1-53. doi:10.1016/S0065-2776(01)79001-3

47. Zinkernagel RM, Leist T, Hengartner H, Althage A. Susceptibility to lymphocytic choriomeningitis virus isolates correlates directly with early and high cytotoxic $\mathrm{T}$ cell activity, as well as with footpad swelling reaction, and all three are regulated by H-2D. J Exp Med (1985) 162(6):2125-41. doi:10.1084/ jem.162.6.2125

48. Ciurea A, Klenerman P, Hunziker L, Horvath E, Senn BM, Ochsenbein AF, et al. Viral persistence in vivo through selection of neutralizing antibody-escape variants. Proc Natl Acad Sci U S A (2000) 97(6):2749-54. doi:10.1073/ pnas. 040558797

49. Silva-Barrios S, Smans M, Duerr CU, Qureshi ST, Fritz JH, Descoteaux A, et al. Innate immune B cell activation by leishmania donovani exacerbates disease and mediates hypergammaglobulinemia. Cell Rep (2016) 15(11):2427-37. doi:10.1016/j.celrep.2016.05.028

50. Allen CD, Ansel KM, Low C, Lesley R, Tamamura H, Fujii N, et al. Germinal center dark and light zone organization is mediated by CXCR4 and CXCR5. Nat Immunol (2004) 5(9):943-52. doi:10.1038/ni1100

51. Bannard O, Horton RM, Allen CD, An J, Nagasawa T, Cyster JG. Germinal center centroblasts transition to a centrocyte phenotype according to a timed program and depend on the dark zone for effective selection. Immunity (2013) 39(5):912-24. doi:10.1016/j.immuni.2013.08.038

52. Moorman JP, Zhang CL, Ni L, Ma CJ, Zhang Y, Wu XY, et al. Impaired hepatitis $B$ vaccine responses during chronic hepatitis $C$ infection: involvement of the PD-1 pathway in regulating CD4(+) T cell responses. Vaccine (2011) 29(17):3169-76. doi:10.1016/j.vaccine.2011.02.052

53. Hannum LG, Haberman AM, Anderson SM, Shlomchik MJ. Germinal center initiation, variable gene region hypermutation, and mutant $\mathrm{B}$ cell selection without detectable immune complexes on follicular dendritic cells. J Exp Med (2000) 192(7):931-42. doi:10.1084/jem.192.7.931

54. Schmittgen TD, Livak KJ. Analyzing real-time PCR data by the comparative C(T) method. Nat Protoc (2008) 3(6):1101-8. doi:10.1038/nprot. 2008.73

55. Chabot S, Fakhfakh A, Beland K, Lamarre A, Oldstone MB, Alvarez F, et al. Mouse liver-specific CD8(+) T-cells encounter their cognate antigen and acquire capacity to destroy target hepatocytes. J Autoimmun (2013) 42:19-28. doi:10.1016/j.jaut.2012.10.002

56. Lopez-Macias C, Kalinke U, Cascalho M, Wabl M, Hengartner H, Zinkernagel RM, et al. Secondary rearrangements and hypermutation generate sufficient B cell diversity to mount protective antiviral immunoglobulin responses. J Exp Med (1999) 189(11):1791-8. doi:10.1084/jem.189. 11.1791

Conflict of Interest Statement: The authors declare that the research was conducted in the absence of any commercial or financial relationships that could be construed as a potential conflict of interest.

Copyright $\odot 2016$ Daugan, Murira, Mindt, Germain, Tarrab, Lapierre, Fritz and Lamarre. This is an open-access article distributed under the terms of the Creative Commons Attribution License (CC BY). The use, distribution or reproduction in other forums is permitted, provided the original author(s) or licensor are credited and that the original publication in this journal is cited, in accordance with accepted academic practice. No use, distribution or reproduction is permitted which does not comply with these terms. 